\title{
Evaluation of Interactions Between Oilfield Chemicals and Reservoir Rocks
}

\author{
E. O. Wuyep ${ }^{1,4}$ G. F. Oluyemi, ${ }^{1}$ K. Yates, ${ }^{2}$ and A. R. Akisanya ${ }^{3}$
}

Received 5 October 2018; accepted 24 June 2019

Published online: 23 July 2019

\begin{abstract}
Sand failure and production occurs when the formation stress exceeds the strength of the formation, which is derived majorly from the natural material that cements the sand grain and cohesive forces. This study investigates the effects of scale inhibitor, biocide and corrosion inhibitor on the geomechanical strength of reservoir rocks (carbonate and sandstone). Integration of geomechanical, petrophysical and analytical techniques is used to establish the failure effects of the interaction of these chemicals on the geomechanical strength of reservoir rocks and failure mechanisms resulting from such interaction. The results confirm that chemical adsorption, dissolution, precipitation and ionic substitution reactions took place between the oilfield chemicals and the formation rocks leading to weakening of the reservoir grain fabrics and reduction in unconfined compressive strength which in turn causes sand failure.
\end{abstract}

KEY WORDS: Rock failure, Geomechanical, Petrophysical, Dissolution, Precipitation.

\section{INTRODUCTION}

Sand failure may result in the production of formation sand at the same time the formation fluids are being produced. This phenomenon is experienced when the sand grains disengage from the rock matrix structure due to mechanical and/or chemical activities. The importance of evaluating the effect of oilfield chemical/reservoir rock interaction on the reservoir geomechanical properties cannot be overemphasized. Understanding the mechanisms of interaction helps to prevent the risk of sand failure

\footnotetext{
${ }^{1}$ School of Engineering, Robert Gordon University, Aberdeen AB10 7GJ, UK.

${ }^{2}$ School of Pharmacy and Life Science, Robert Gordon University, Aberdeen AB10 7GJ, UK.

${ }^{3}$ School of Engineering, University of Aberdeen, Aberdeen AB24 3UE, UK.

${ }^{4}$ To whom correspondence should be addressed; e-mail: e.o.wuyep@rgu.ac.uk
}

and sand production potential that is associated with the phenomenon.

Oilfield operational activities expose reservoir rocks to a range of oilfield chemicals. However, the negative effects on the reservoir geomechanical properties are not always fully considered. Therefore, it is imperative to evaluate the geomechanical effects of these oilfield chemicals on the properties of the reservoir rock to be able to develop accurate sand failure prediction models (Oluyemi et al. 2010). Chemical-rock interaction occurs via adsorption, which is the binding of chemical to the rock (substrate) surface through Van der Waal forces. The dissolution and precipitation phenomena that take place as a result of chemical-reservoir rock interaction are capable of altering the porosity and permeability of the reservoir rock ( $\mathrm{Li}$ and Aubertin 2003). The alteration, which could result in a decrease or an increase in these rock properties depending on the mineral composition of the rock, particle size distribution, shape of the particle and 
pore size, can also affect the storage capacity of the reservoir rock (Lamy-Chappuis et al. 2014).

A number of studies have been undertaken to evaluate the effects of interaction between reservoir rocks and chemicals on the properties of these rocks. Yang et al. (2017) examined the evolution of reservoir property during diagenesis using sandstone core samples interaction with brine/acetic acid and showed that most minerals, for instance, calcite, feldspar, etc., dissolved leading to porosity increase. Analysis of flow-back water from shale by Wilson (2016) to investigate the source of ions and the mechanisms involved in the chemistry of flow-back water in water/shale interaction showed leaching of clay and dissolution of rock constituents as the possible source of ions observed in the flow-back water. Evaluation of the petrophysical properties of carbonate rocks altered by rock-fluid interaction using $\mathrm{CO}_{2}$ revealed that permeability evolution is a function of the degree of dissolution and is highly dependent on the pore structure (Egermann et al. 2010). One common limitation in these studies is that the chemistries of the chemicals used are different from that of commonly deployed oilfield chemicals. Consequently, the findings from these studies cannot be reliably used to predict the effects of commonly used oilfield chemicals on the failure of reservoir rocks.

Tomson et al. (2008) studied rock-phosphonate inhibitor interaction and the effect of metal ions on inhibitor retention under dynamic condition and revealed that inhibitor squeeze treatment can be improved by adding a compatible cation to control the acidity of the inhibitor pill. Oluyemi (2014) conducted a laboratory experiment on clashach cores under dynamic condition to investigate the likely effects of scale inhibitors (PTEMP) on the geomechanical strength and sand production potentials of sandstone reservoir. The results revealed sand failure and release of particles into the flow stream. The following shortcomings are identified with the results presented in Oluyemi (2014) that necessitated the current investigation:

1. The work focused only on the scale inhibitor and sandstone. It is difficult to use the result to explain the effect of interaction of other commonly used oilfield chemicals with sandstone and carbonates on the formation rock strength.

2. Mechanical tests were not conducted to define the failure mechanism and confirm the effect of the chemical on the geomechanical strength.

Kan et al. (2004) assessed the factors affecting scale inhibitor retention in carbonate-rich formation during squeeze treatment. The results showed that the extent of inhibitor retention by carbonate-rich formation rock is limited by the amount of calcite that can dissolve prior to inhibitor-induced surface poisoning. In further study by Kan et al. (2005), adsorption and precipitation of an aminoalkyphosphonate onto calcite to quantify the interaction of phosphonates with calcite and relate phosphonate retention/release from formation material showed that after multiple layers of phosphonate are formed on the calcite surface, the solution is no longer at equilibrium with calcite. A core-flooding experiment to study the effect of scale inhibitor (SI) concentration and $\mathrm{pH}$ on the inhibitor adsorption and on the evolution of the inhibitor and cation (calcium and magnesium) during inhibitor/carbonate rock interactions showed that the higher the concentration of $\mathrm{SI}$ and the lower the $\mathrm{pH}$, the more calcium dissolution is observed in the system (Baraka-Lokmane and Sorbie 2010).

Another study to investigate the binding, adsorption and film formation of imidazoline to iron carbonate during the interaction between corrosion inhibitors and iron carbonate revealed that inhibitor film formation onto non-conductive material like iron carbonate $\left(\mathrm{FeCO}_{3}\right)$ may strengthen the corrosion product film, reducing its porosity and retarding transport of reactants to the corroding surface ( $\mathrm{Ra}-$ machandran et al. 1999). Despite the efforts made by these authors to explore the interaction between the scale/corrosion inhibitors and the formation rocks, questions regarding the effects of the interaction between the scale inhibitor, corrosion inhibitor, biocide and the formation rock on the geomechanical strength of the rocks, and the mechanisms of interaction still remained unanswered.

Wuyep et al. (2018) conducted studies on the interaction of betaine, aminotri (methylene phosphonic acid)_ATMP and glutaraldehyde with sandstone and limestone to determine their effects on the geomechanical strength of these rocks. The study was done under static condition which is purely diffusion transport driven. However, the saturation under static condition only simulates "shut in" period during chemical placement in the field, which does not account for the effect of fluid 
flow. Dynamic saturation, which involves injection and flushing out of the chemicals (flow-back) at a determined flow rate, mimics production from the reservoir formation following chemical injection. Further, Wuyep et al. (2018) did not consider the effect of the oilfield chemicals on the petrophysical properties of the rocks.

The current paper is an extension of the work of Wuyep et al. (2018) and seeks to investigate the effects of scale inhibitor, biocide and corrosion inhibitor on the geomechanical strength of reservoir rocks under dynamic condition (convection and diffusion transport) and explore the geomechanical failure mechanisms arising from the interaction of these chemicals with reservoir rocks using an integrated approach.

\section{EXPERIMENTAL METHODS}

\section{Materials}

Thirty (30) core samples, fifteen (15) each of clastic (sandstone) and carbonates, were used for this study. The samples have a cylindrical shape with a nominal length of $51 \pm 0.5 \mathrm{~mm}$ and a nominal diameter of $38 \pm 0.49 \mathrm{~mm}$. The cores were sourced from Kocurek Industries Ltd at a depth of $\sim 183 \mathrm{~m}$, and they are believed to have their origin from Texas, USA. The leopard sandstone and Edward brown carbonate core samples are identified as LP $n$ and $\mathrm{ED} n$, respectively, where $n(1-15)$ is the sample number. The injected chemicals-scale inhibitor (aminotri (methylene phosphonic acid)-ATMP), biocide (glutaraldehyde) and corrosion inhibitor (betaine)-were obtained from REDA Oilfield UK Ltd.

\section{Dynamic Saturation}

Saturation under dynamic condition gives an opportunity to demonstrate the flow of reacting fluid to and through the rock surface by diffusion and convection. The process involves collection of uptake and flow-back effluents. The flow-back effluents were analyzed to investigate the release of cations/particles and mechanisms controlling the flow-back chemistry. The flow experiment involved saturation of the rocks in synthetic formation brine prior to exposure of the core samples to the test chemicals. The saturating brine was prepared in concentrations that simulate typical formation water; the active ions in the brine are presented in Table 1. The prepared brine was filtered through a $40-\mu \mathrm{m}$ sintered glass filter to remove any extraneous fines that may be present before use.

Each core sample was then assembled in a core holder and attached to the core-flooding rig. To ensure a laminar flow regime that would stabilize the fines in the clay minerals, each core sample was saturated with brine at $1 \mathrm{~mL} / \mathrm{min}$ for six (6) hours prior to chemicals injection. The choice of six (6) hours was to ensure saturation and cleaning of the core sample prior to chemical injection. The establishment of the saturation time and flow rate was based on calibration in this study and previous work by Oluyemi (2014).

Lithium tracer technique was used to measure the porosity of the cores pre- and post-chemical treatment. The choice of lithium tracer technique was informed by the fact that it is an inert metal and does not interact with the core minerals.

Individual stock solutions of $1 \mathrm{wt} \%$ corrosion inhibitor (betaine) and biocide (glutaraldehyde) were prepared by diluting $2.5 \mathrm{~g}$ of each of the chemicals in $250 \mathrm{ml}$ of the prepared brine. Also, a stock solution of $5 \mathrm{wt} \%$ scale inhibitor (aminotri (methylene phosphonic acid)-ATMP) was prepared by diluting $12.50 \mathrm{~g}$ of the ATMP in $250 \mathrm{ml}$ of the brine. The choice of the concentration of the corrosion and scale inhibitors is based on typical values used in field application. The $\mathrm{pH}$ of the brine, chemical solutions and effluents were measured at room temperature (approx. $20^{\circ} \mathrm{C}$ ).

Each chemical solution (betaine, ATMP and glutaraldehyde) was injected into the core sample at a flow rate of $0.25 \mathrm{~mL} / \mathrm{min}$ to full saturation using

Table 1. Brine composition (modified after Jordan and Sjursaether (2005) and Vazquez et al. (2016)

\begin{tabular}{lcccccccrr}
\hline Element & $\mathrm{Na}^{+}$ & $\mathrm{K}^{+}$ & $\mathrm{Ca}^{2+}$ & $\mathrm{Mg}^{2+}$ & $\mathrm{Ba}^{2+}$ & $\mathrm{Sr}^{2+}$ & $\mathrm{Cl}^{-}$ & $\mathrm{SO}_{4}^{2-}$ & $\mathrm{HCO}_{3}^{2-}$ \\
\hline Concentration $(\mathrm{ppm})$ & 24,870 & 887 & 785 & 561 & 108 & 3 & 39,800 & 35 & 2014 \\
\hline
\end{tabular}


the determined pore volume for each core sample, and the effluent (uptake) was collected. After full saturation with the chemical was achieved, the inlet and outlet valves were shut and the core was left to stand for $24 \mathrm{~h}$ ("shut in" period) to allow longer interaction (Oluyemi 2014). Subsequently, brine was used to flush the chemicals out of the core with the same measured pore volume prior to the chemical injection and the effluent (flow-back) was also collected. The core was then removed from the core holder after the flush out with brine, rinsed with deionized water and oven-dried for 3 days to constant weight at $106{ }^{\circ} \mathrm{C}$ which is the recommended temperature for rocks (Verwall and Mulder 2000). This was replicated for three samples each of sandstone and carbonate for each chemical treatment.

\section{Mechanical Testing}

Uniaxial compression test was conducted on the core samples to determine the uniaxial compressive strength (UCS) of the rock pre- and post-chemical treatment. Oven-dried chemically treated samples were used for the post-chemical treatment mechanical testing. Strain gauge was attached to each core sample for the measurement of the axial strain and determination of Young's modulus $(E)$.

The uniaxial compression test was carried out in displacement control at a nominal rate of $0.5 \mathrm{~mm} / \mathrm{min}$, which is equivalent to a nominal strain rate of $1.6 \times 10^{-4} \mathrm{~s}^{-1}$, using a screw-driven mechanical test machine Instron ${ }^{\circledR}$ Model 3382 that has a load capacity of $100 \mathrm{kN}$. The weight, length and diameter of the cores were measured and recorded prior to the tests. The load and the corresponding crosshead displacement were continuously recorded using the built-in data logger of the test machine. The test procedure is in accordance with the recommendations of the International Society for Rock Mechanics (ISRM) (Bieniawski and Bernede 1979). The stress-strain curve for the UCS was obtained using the strain generated from the crosshead displacement data, while that of the Young's modulus was obtained using the strain measured from the strain gauge vs. stress response.

\section{Analytical Studies}

Scanning electron microscopy (SEM), energydispersive X-ray spectroscopy (EDX) and X-ray powder diffraction (XRPD) analyses of oven-dried treated and untreated rock core samples were carried out. The objective of these analyses was to identify and analyze any chemical changes that might have taken place within the rock fabric and the corresponding mechanical damage to the rock fabric. The SEM, EDX and XRPD analyses were carried out as described in Wuyep et al. (2018).

\section{Particle Size Distribution Analysis}

The distribution of particle size in the original brine, brine and chemical effluents collected from the dynamic saturation was determined using a Malvern Laser Mastersizer 2000s to evaluate the range of particle sizes that have been released into the fluid streams. Each effluent sample (uptake and flow-back) was stirred with magnetic stirrer, and with the use of a dropper, was fed into the Malvern Laser Mastersizer to ensure the entire range of particle sizes in the original brine, and the effluents were adequately captured.

\section{RESULTS AND DISCUSSION}

\section{Chemical Composition and Mineralogy of Rock Samples}

The sandstone under consideration was found to have well-sorted, rhombic to orthorhombic detrital quartz minerals coated with clay minerals (white dotted circle) under SEM (Fig. 1a). This is confirmed by the EDX scan showing high traces of silicon $(30.38 \mathrm{wt} \%)$ and oxygen $(64.23 \mathrm{wt} \%)$ in Figure $1 \mathrm{~b}$ and Table 2. Other elements present in the untreated sandstone are $\mathrm{Na}(0.43 \mathrm{wt} \%), \mathrm{Al}$ (3.00 wt \%), $\mathrm{Cl}(0.30 \mathrm{wt} \%), \mathrm{K} \quad(0.87 \mathrm{wt} \%), \quad \mathrm{Fe}$ $(0.50 \mathrm{wt} \%)$ and $\mathrm{Ag}(0.29 \mathrm{wt} \%)$. The clay content is indicated by the presence of $\mathrm{Al}$ and $\mathrm{Na}$, while the presence of $\mathrm{K}, \mathrm{Al}$ and $\mathrm{Na}$ is an indication that the sample contains feldspar. The presence of quartz mineral is further confirmed by bulk mineralogical result from XRPD (Fig. 2a; Table 3). The result shows a quartz content of $98.4 \mathrm{wt} \%$ with the other minerals such as plagioclase, calcite, halite and illite plus illite/smectite mixed layer (I + I/S-ML) taking up the remaining $1.6 \mathrm{wt} \%$.

Similarly, the SEM image of the cross section of the carbonate sample reveals a partially dolomitized limestone with moderately sorted euhedral-subhe- 


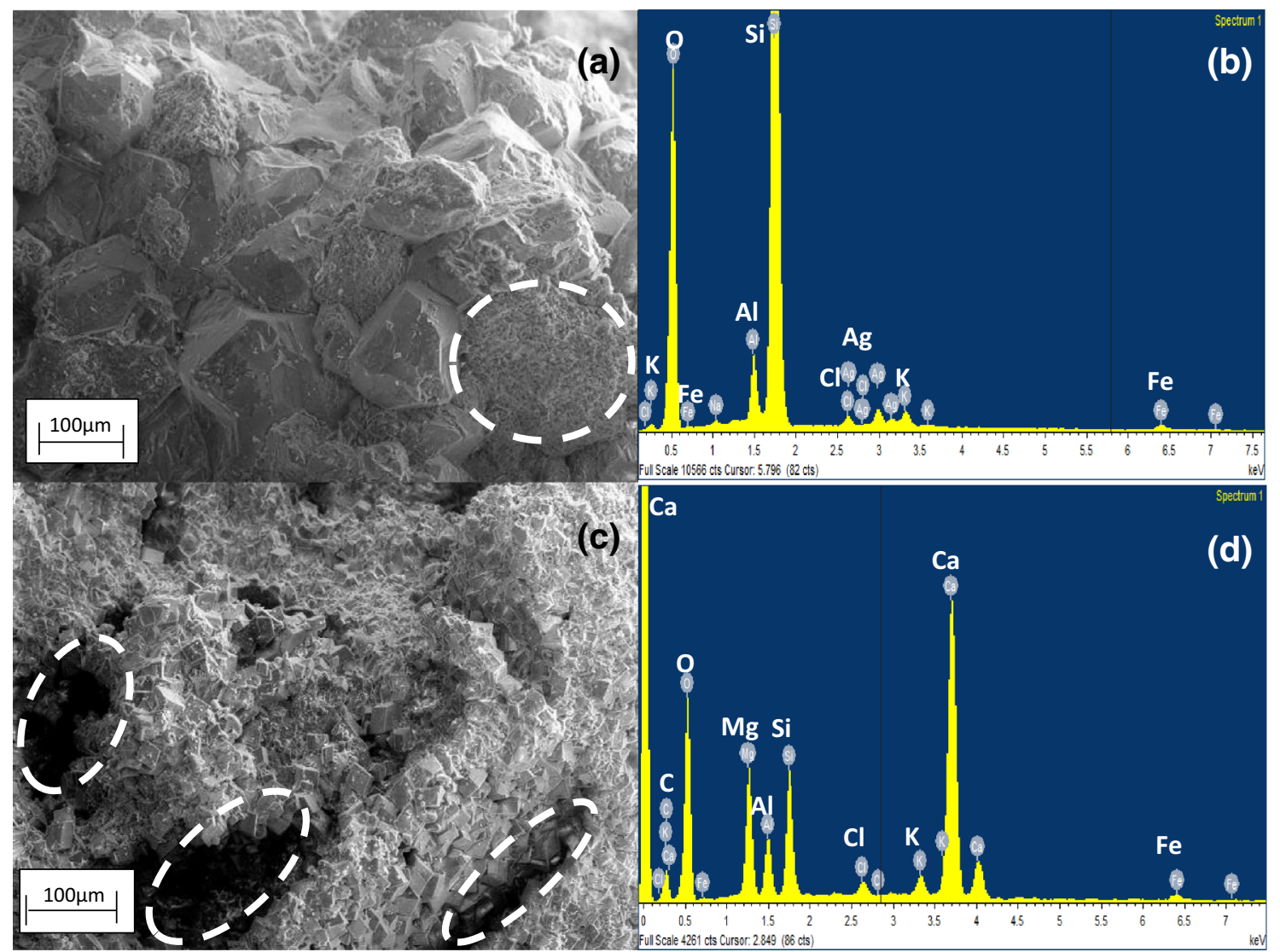

Figure 1. SEM and EDX characterization of untreated samples: (a) sandstone sample LP1 showing detrital quartz minerals coated with clay minerals within the white dotted circle; (b) sandstone EDX spectrum; (c) carbonate sample ED1 showing large voids indicated by the dotted ellipse; (d) carbonate, EDX spectrum showing the peaks of various elements.

dral dolomite minerals with sucrosic texture and vugs (Fig. 1c). The dolomite content is confirmed by EDX scan showing high traces of calcium $(\mathrm{Ca})$, oxygen $(\mathrm{O})$, magnesium $(\mathrm{Mg})$ and carbon $(\mathrm{C})$ as shown in Figure 1d and Table 2. XRPD bulk mineralogy of carbonate sample, for example ED1, confirmed that the core contains high proportion of dolomite $(73.8 \mathrm{wt} \%)$ and $26.2 \mathrm{wt} \%$ of other minerals like calcite (21.2 wt \%), quartz (3.7 wt $\%)$, I + I/SML (0.9 wt\%), pyrite and halite (Fig. 2c; Table 3).

Clay fraction identification (Table 4) of the $<2 \mu \mathrm{m}$ fractions shows the presence of kaolinite $(14 \%)$, illite $(35 \%)$ and illite/smectite mixed layer $(51 \%)$ in the untreated sandstone (Fig. 2b). The clay fraction for the untreated carbonate was found to consist of $7 \%$ kaolinite, $7 \%$ illite and $86 \%$ illite/ smectite mixed layer (Fig. 2d).

Depending on the magnitude of the interaction between the rock and the chemicals, there is a possibility that these parameters (rock texture, strength, mineral and element composition) will alter due to chemical interaction. Furthermore, a change in $\mathrm{pH}$ of the system appears to have some implications on the dissolution of rock minerals. Bunny et al. (1997) for example suggested that injection of fluids with $\mathrm{pH}$ value greater than 4.5 tends to lower the dissolution rate of carbonate rocks.

\section{Effect of Chemicals on Porosity and Permeability of Sandstone and Carbonate}

Rock materials like other natural or man-made materials display some mechanical behavior under certain conditions that depend on their internal structure. Figure $3 \mathrm{a}$ and $\mathrm{b}$ shows typical lithium tracer profiles from which the porosities of sandstone and carbonates were calculated, respectively. At least nine data points were recorded for each lithium profile, and equilibrium was achieved for all the profiles when the cumulative volume attained approximately $20 \mathrm{~mL}$ (Fig. 3a and b). Figure $3 \mathrm{c}$ and 
Table 2. Elemental composition of sandstone and carbonate cores pre- and post-chemical treatment

\begin{tabular}{|c|c|c|c|c|c|}
\hline Elements & Untreated (wt\%) & Brine (wt \%) & Betaine (wt \%) & ATMP (wt\%) & Glutaraldehyde (wt\%) \\
\hline \multicolumn{6}{|c|}{ Sandstone } \\
\hline $\mathrm{O}$ & 64.20 & 62.90 & 64.2 & 63.9 & 58.00 \\
\hline $\mathrm{Na}$ & 0.43 & ND & ND & 4.43 & 1.74 \\
\hline $\mathrm{Al}$ & 3.00 & 3.24 & 2.15 & 3.11 & 3.00 \\
\hline $\mathrm{Si}$ & 30.38 & 31.10 & 32.6 & 23.10 & 29.70 \\
\hline $\mathrm{Cl}$ & 0.30 & 0.41 & 0.15 & 4.44 & 2.42 \\
\hline $\mathrm{K}$ & 0.87 & 0.57 & 0.32 & 0.36 & 0.47 \\
\hline $\mathrm{Fe}$ & 0.50 & 1.11 & 0.47 & 0.28 & 1.51 \\
\hline $\mathrm{Ag}$ & 0.29 & 0.21 & ND & ND & ND \\
\hline $\mathrm{Ti}$ & ND & ND & 0.18 & ND & 0.22 \\
\hline $\mathrm{Mg}$ & ND & ND & ND & 0.19 & ND \\
\hline $\mathrm{P}$ & ND & ND & ND & 0.19 & ND \\
\hline $\mathrm{C}$ & ND & ND & ND & ND & 1.50 \\
\hline $\mathrm{Mn}$ & ND & 0.48 & ND & ND & 1.44 \\
\hline Total & 100 & 100 & 100 & 100 & 100 \\
\hline \multicolumn{6}{|c|}{ Carbonate } \\
\hline $\mathrm{C}$ & 5.16 & 2.76 & 2.07 & 5.69 & 5.76 \\
\hline $\mathrm{O}$ & 70.20 & 70.7 & 66.80 & 70.90 & 69.70 \\
\hline $\mathrm{Mg}$ & 5.79 & 6.46 & 7.33 & 6.43 & 6.57 \\
\hline $\mathrm{Al}$ & 2.20 & 1.79 & 2.18 & 1.36 & 1.26 \\
\hline $\mathrm{Si}$ & 4.30 & 5.47 & 4.73 & 3.21 & 2.97 \\
\hline $\mathrm{Cl}$ & 0.44 & 0.27 & 0.73 & 0.18 & 1.16 \\
\hline $\mathrm{K}$ & 0.65 & 0.61 & 0.52 & 0.34 & 0.33 \\
\hline $\mathrm{Ca}$ & 10.9 & 16.40 & 18.70 & 11.20 & 10.6 \\
\hline $\mathrm{Fe}$ & 0.38 & 0.86 & 0.92 & 0.43 & 0.30 \\
\hline $\mathrm{Na}$ & ND & ND & ND & ND & 1.36 \\
\hline $\mathrm{P}$ & ND & ND & ND & 0.30 & ND \\
\hline $\mathrm{Ag}$ & ND & 0.20 & 0.19 & ND & ND \\
\hline Total & 100 & 100 & 100 & 100 & 100 \\
\hline
\end{tabular}

$N D$ Not detected

d shows the differential pressure profiles obtained from the permeability measurement during the flow test for sandstone and carbonates, respectively. The striking similarities in both sandstone and carbonate profiles are an indication that there are no significant differences in the flow properties of both rocks. Recall that porosity and permeability were measured for three separate nominally identical specimens for each of the chemicals considered, and the average of the three measurements is shown in Figure $3 \mathrm{e}$ and $\mathrm{f}$. We note an increase in the average porosity of sandstone from $15 \pm 1.5$ in brine to $25 \pm 4,28 \pm 0.7$ and $24 \pm 5 \%$ after the injection of ATMP, betaine and glutaraldehyde, respectively (Fig. 3e). There was a corresponding increase in brine permeability from $76 \pm 11.5$ to $88 \pm 2.8$, $224 \pm 27.6$ and $92 \pm 16 \mathrm{mD}$ upon injection of ATMP, betaine and glutaraldehyde, respectively.

In Figure 3f, a decrease in mean porosity of the carbonates from $28 \pm 1$ to $21 \%$; 22 and $19 \%$ was observed following injection of ATMP, betaine and glutaraldehyde, respectively. A decrease in permeability from $107 \pm 1$ to $79 \pm 18$ and $66 \pm 8 \mathrm{mD}$ was also observed owing to treatment with ATMP and betaine, respectively. However, an increase in permeability from 107 to $153 \pm 32.7 \mathrm{mD}$ was recorded following treatment with glutaraldehyde.

As a check on the accuracy of the porosity measurement based on the lithium tracer, the porosity of the sandstone prior to chemical treatment was also determined using the weight method. The average weight of the sandstone samples prior to chemical treatment was $117 \mathrm{~g}$, and the XRPD results in Table 3 shows that the sandstone is made up of $98 \mathrm{wt} \%$ of quartz. Neglecting the $2 \mathrm{wt} \%$ of the other minerals in the sandstone, the porosity, $\Phi$, can be shown to be given by $\lambda=\left(1-\frac{m_{\mathrm{c}}}{\rho_{\mathrm{s}} V_{\mathrm{s}}}\right)$, where $m_{\mathrm{c}}=117 \mathrm{~g}$ is the mass of the core, $V_{\mathrm{s}}\left(=57.8 \mathrm{~cm}^{3}\right)$ is the volume of the core based on the specimen dimensions, and $\rho_{\mathrm{s}}$ is the density of quartz which is between $\rho_{\mathrm{s}}=2.3$ and $\rho_{\mathrm{s}}=2.45 \mathrm{~g} / \mathrm{cm}^{3}$ (CES Edu- 

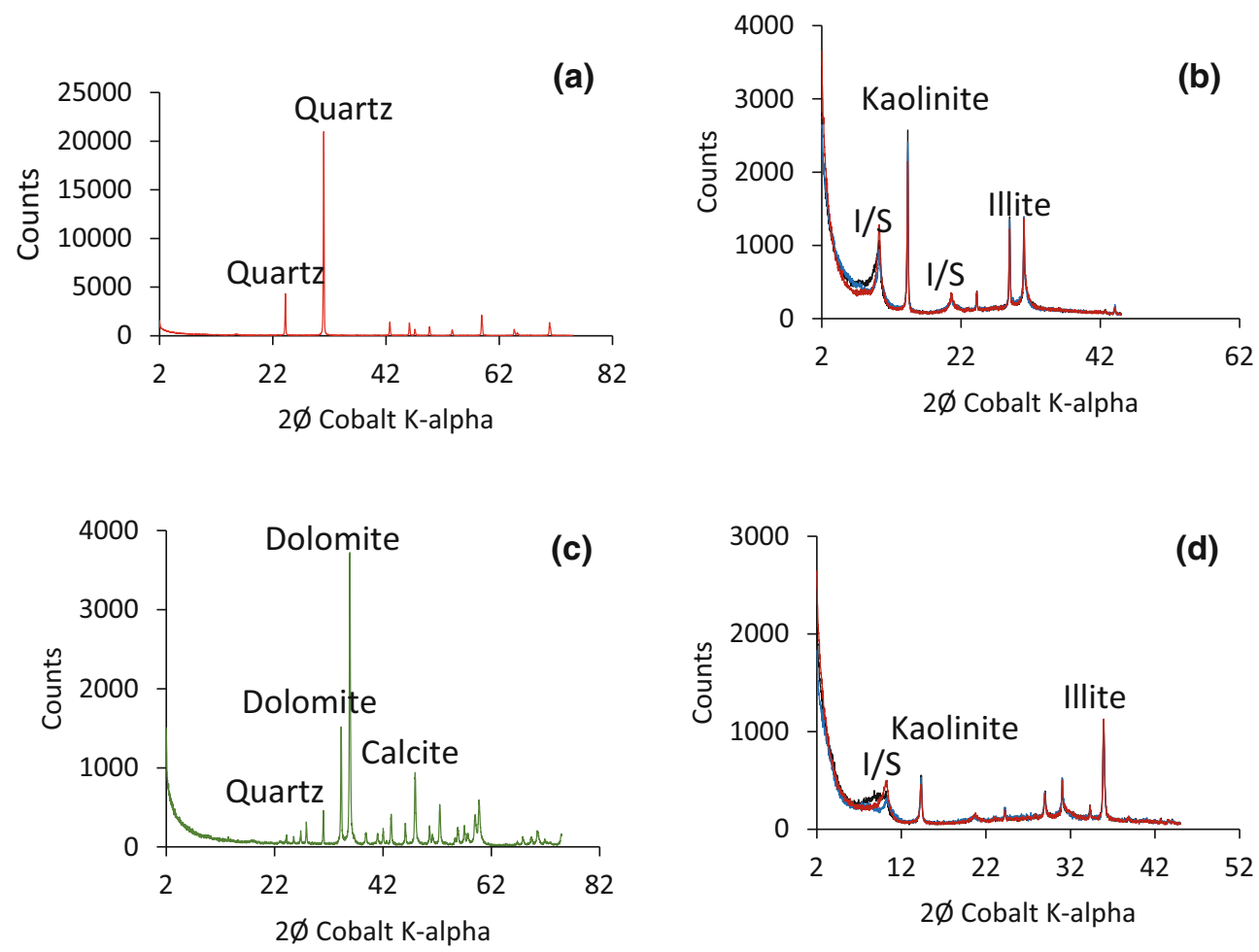

Figure 2. XRPD bulk mineralogy and clay fraction analyses of untreated samples: (a) bulk analysis of sandstone, (b) clay fraction analysis of sandstone, (c) bulk analysis of carbonate and (d) clay fraction analysis of carbonate.

Table 3. XRPD bulk mineralogy (wt \%) based on reference intensity ratio (RIR) method

\begin{tabular}{lcclccccccc}
\hline Sample ID & Quartz & Plagioclase & K-feldspar & Calcite & Dolomite & Pyrite & Halite & I + I/S-ML & Kaolinite & Total \\
\hline LP-Untreated & 98.4 & 0.2 & 0.0 & 0.4 & 0.0 & 0.0 & 0.2 & 0.8 & Trace & 100.0 \\
LP-Brine & 98.5 & 0.3 & 0.0 & 0.1 & 0.0 & 0.0 & 0.2 & 0.9 & Trace & 100.0 \\
LP-Betaine & 98.0 & 0.2 & 0.0 & 0.1 & 0.0 & 0.0 & 0.1 & 0.8 & 0.8 & 100.0 \\
LP-ATMP & 98.4 & 0.4 & Trace & 0.2 & 0.0 & 0.0 & 0.1 & 0.8 & 0.1 & 100.0 \\
LP-Glut & 98.0 & 0.4 & 0.0 & 0.4 & 0.0 & 0.0 & 0.2 & 0.4 & 0.6 & 100.0 \\
ED-Untreated & 3.7 & 0.0 & 0.0 & 21.2 & 73.8 & 0.2 & 0.2 & 0.9 & 0.0 & 100.0 \\
ED-Brine & 4.0 & 0.0 & 0.0 & 2.3 & 92.6 & 0.0 & 0.8 & 0.3 & 0.0 & 100.0 \\
ED-Betaine & 4.2 & 0.0 & 0.0 & 2.2 & 93.0 & 0.0 & 0.3 & 0.3 & 0.0 & 100.0 \\
ED-ATMP & 3.8 & 0.0 & 0.0 & 1.6 & 93.6 & 0.1 & 0.7 & 0.2 & 0.0 & 100.0 \\
ED-Glut & 2.8 & 0.0 & 0.0 & 1.6 & 95.1 & 0.0 & 0.3 & 0.2 & 0.0 & 100.0 \\
\hline
\end{tabular}

LP Leopard (sandstone), ED Edward brown (carbonate), ATMP aminotri (methylene phosphonic acid), Glut glutaraldehyde

pack 2018). The porosity of the sandstone prior to chemical treatment based on the weight is therefore in the range between 12 and $17 \%$; this is consistent with the value of $15 \%$ obtained using the tracer method.

The post-chemical treatment increase in the porosity and permeability of the sandstone observed in the current study suggests enlargement of pore space due to dissolution of grain fabrics (Přikryl 2001; Benavente et al. 2004; Török and Vásárhelyi 2010). The increase could have emanated from the dissolution of the clay minerals that form part of the rock matrix. The main driving force that causes heterogeneous chemical reactions at the interface between the pore fluid and the rock minerals or the materials that cement the rock grain fabrics is the 
Table 4. Relative percentage of clay minerals in the $<2 \mu$ m clay size fraction

\begin{tabular}{lccc}
\hline Sample ID & Kaolinite & Illite & I/S-ML \\
\hline LP-Untreated & 14 & 35 & 51 \\
LP-Brine & 19 & 19 & 62 \\
LP-Betaine & 23 & 12 & 65 \\
LP-ATMP & 17 & 15 & 68 \\
LP-Glut & 23 & 13 & 64 \\
ED-Untreated & 7 & 7 & 86 \\
ED-Brine & 10 & 6 & 84 \\
ED-Betaine & 10 & 4 & 84 \\
ED-ATMP & 9 & 5 & 86 \\
ED-Glut & 8 & 6 & 86 \\
\hline
\end{tabular}

$L P$ Leopard (sandstone), ED Edward brown (carbonate), ATMP aminotri (methylene phosphonic acid), Glut glutaraldehyde

pore fluid flow, which carries the reactive aqueous species. The interaction between this reactive aqueous fluid and either the mineral components of the rock or the cement material causes dissolution of one mineral and precipitation of another leading to alteration of initial porosity and permeability.

A decrease in porosity and permeability, which signifies constriction/obstruction of pore spaces due to formation of new minerals (precipitates), is observed in carbonate treated with ATMP and betaine. The observed decrease could be as a result of precipitation and dispersion of small grains between large ones within the pores (Nimmo 2004). Previous work (Xue et al. 2004) has proven that constant molar precipitation reaction can lead to porosity reductions. Precipitation of new materials originates from the continuous interaction of the de-bonded materials with other particles. The interaction of glutaraldehyde with carbonates that produced a decrease in porosity and an increase in permeability could have been caused by variations in the grain size of the precipitated materials. Such observation has been reported by Nelson (1994) and Bernabé et al. (2003). Furthermore, different pores give different contributions to permeability of the material according to their shape and size (Bernabé et al. 2003).

Pore space enlargement could lead to the weakening of the grain fabrics resulting in strength reduction, while constriction due to precipitation/ release of material that may be weaker than the original material into the fluid stream leads to pore clogging with consequential low wellbore performance and formation damage. Of the three oilfield chemicals considered in the current study, betaine demonstrated the most significant detrimental effect on the petrophysical properties of the two types of formation rock than ATMP and glutaraldehyde.

\section{Particle/Grain Detachment}

The grain size distribution profiles (Fig. 4) of the sandstone and carbonate under dynamic saturation show no substantial difference in shape and value between the original brine and brine effluents. Nevertheless, there are changes in $\mathrm{D}_{10}, \mathrm{D}_{50}$ and $\mathrm{D}_{90}$ values of the grain size distributions profile of the chemical uptake and flow-back effluents, see Table 5. The slight increase in values of $D_{50}$ and $D_{90}$ for the chemical flow-back observed in this work may be attributed to the low flow rate used. The key grain size parameters of the size distribution profiles of the brine effluents from both core samples suggest the particles originated from the fines that were less than the glass filter openings can filter. Comparing these results with the mechanical and analytical test results, it is obvious that the level of deterioration with the brine treated cores is much less than that of the chemically treated cores. This is evidenced by the release of comparatively lower amount of particles into the brine during the test. However, there is a remarkable difference in the grain size parameters between the brine effluents and the three chemical effluents (see Fig. 4a and b; and Table 5). In particular, the chemical effluents appear to exhibit broader grain size distribution profiles with poorer sorting (Folk 1966) in contrast to the original brine. It is evident from Figure 4 that there was a release of some particles into the various chemical solutions during the tests. These results indicate possible failure of the chemically treated cores due to the associated shear force generated by the superficial velocity of the fluids in the pores being greater than the formation strength can bear as simulated by the chemical flow-back. This led to release of a wide range of particles into the flow streams. Increased proportion of particles in the effluent typically implies widening of the pore space and increase in porosity and permeability, leading to reduction in the uniaxial compressive strength. On the other hand, the released particles, which are obviously weaker than the original particles could fill the pore space, reduce porosity and permeability, resulting in formation damage and low productivity. There are therefore two competing mechanisms; the macroscopic response of the core, 

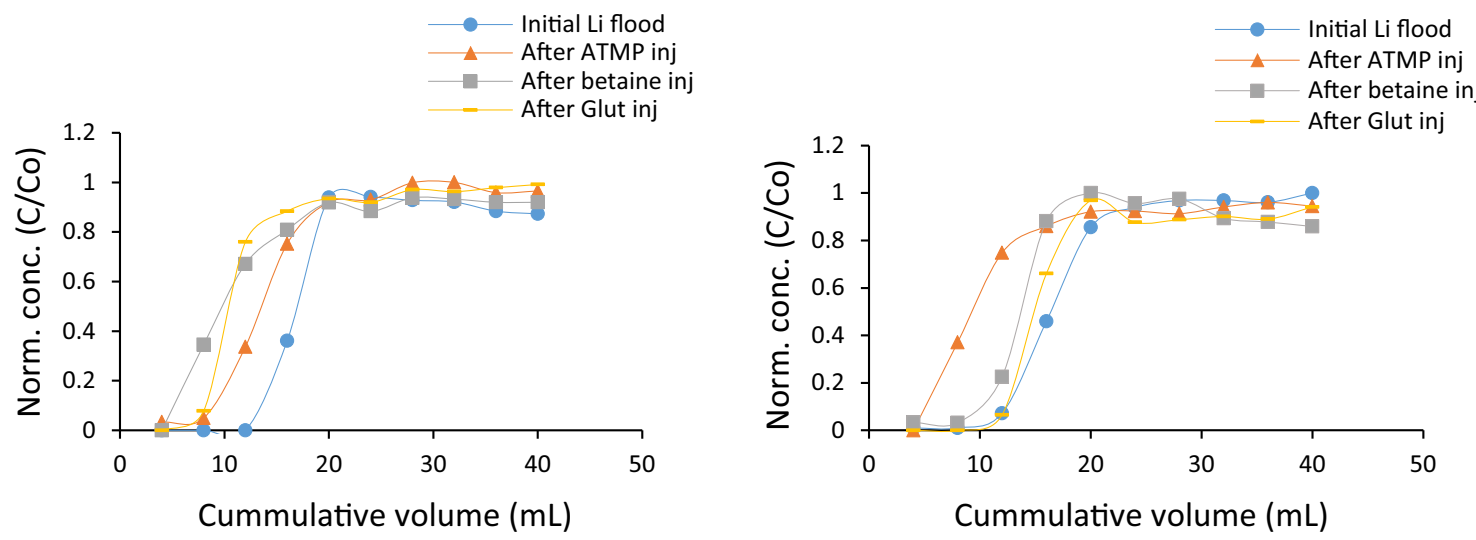

(a)

(b)

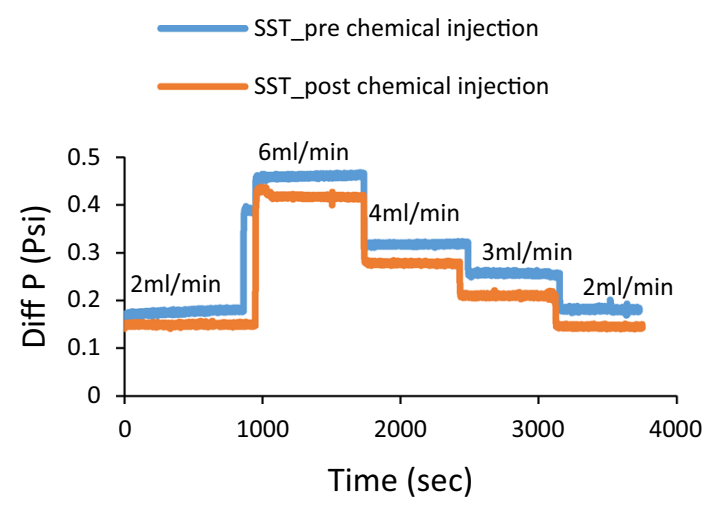

(c)

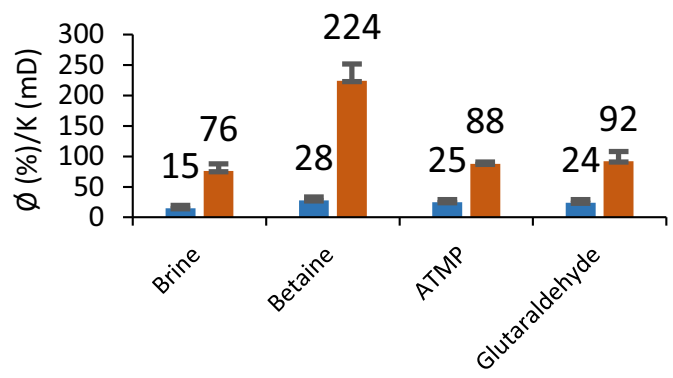

Average Porosity (\%) AveragePermeability (mD)

(e)

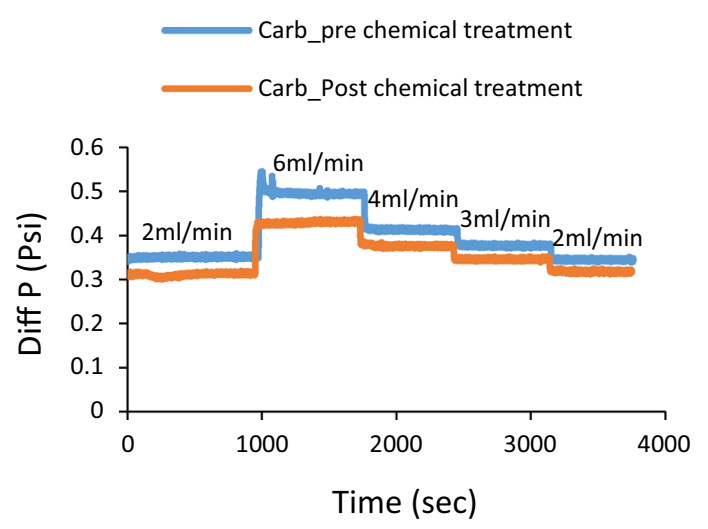

(d)

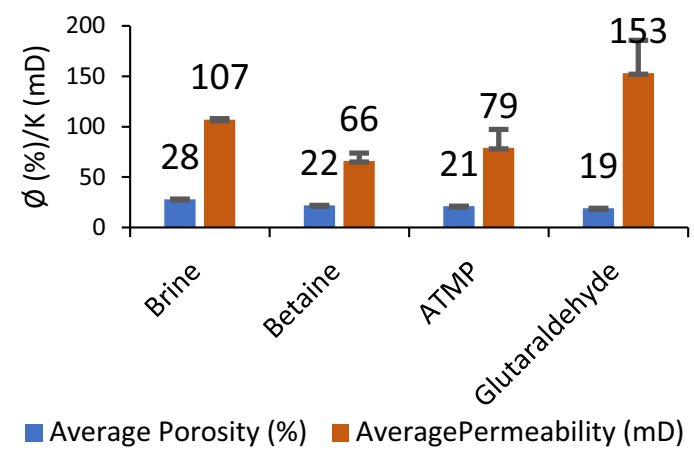

(f)

Figure 3. Pre- and post-injection petrophysical characterization: (a) lithium tracer profile for sandstone; (b) lithium tracer profile for carbonate, where Co and $\mathrm{C}$ represent initial and final lithium concentrations; (c) differential pressure profile during sandstone permeability measurement; (d) differential pressure profile during carbonate permeability measurement; (e) average porosity and permeability of sandstone; (f) average porosity and permeability of carbonate.

which is the focus of the current study, will depend on the most dominant of the two mechanisms. Detailed microscopic study, for example using micro-
CT, would be needed to quantify the local particle transport in the pore network of the core. The determination of the specific location of dissolution 


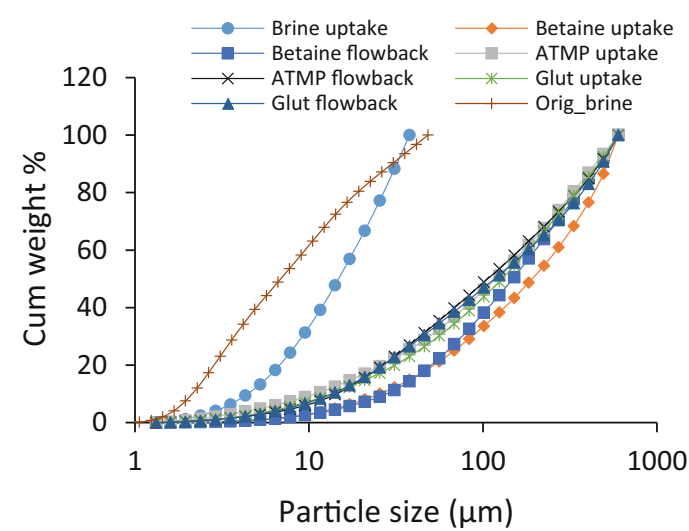

(a)

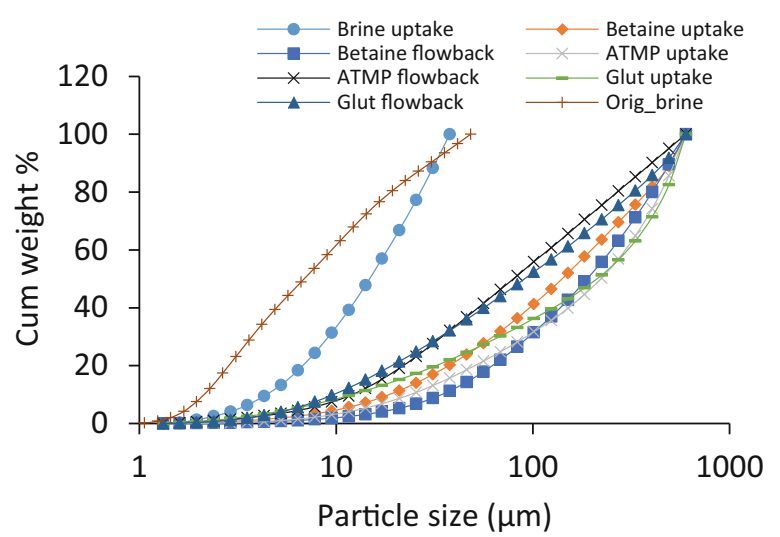

(b)

Figure 4. Grain size distribution profiles of original brine, brine and chemical uptake and flow-back effluents under dynamic condition: (a) sandstone, and (b) carbonate.

Table 5. $\mathrm{D}_{10}, \mathrm{D}_{50}, \mathrm{D}_{90}$ and sorting of original brine, brine and chemical uptake and flow-back effluents under dynamic condition (sandstone and carbonate)

\begin{tabular}{|c|c|c|c|c|c|}
\hline Effluents & $\mathrm{D}_{10}(\mu \mathrm{m})$ & $\mathrm{D}_{50}(\mu \mathrm{m})$ & $\mathrm{D}_{90}(\mu \mathrm{m})$ & & б1) (Folk 1966) \\
\hline \multicolumn{6}{|l|}{ Sandstone } \\
\hline Original brine & 2 & 7 & 32 & 0.36 & Well sorted \\
\hline Brine uptake & 2 & 20 & 40 & 0.82 & Moderately sorted \\
\hline Betaine uptake & 27 & 150 & 430 & 1.58 & Poorly sorted \\
\hline Betaine flow-back & 27 & 180 & 500 & 1.97 & Poorly sorted \\
\hline ATMP uptake & 12 & 100 & 420 & 1.99 & Poorly sorted \\
\hline ATMP flow-back & 14 & 133 & 433 & 1.89 & Poorly sorted \\
\hline Glutaraldehyde uptake & 14 & 100 & 430 & 1.99 & Poorly sorted \\
\hline Glutaraldehyde flow-back & 14 & 100 & 500 & 2.10 & Very poorly sorted \\
\hline \multicolumn{6}{|l|}{ Carbonate } \\
\hline Original brine & 2 & 7 & 30 & 0.36 & Well sorted \\
\hline Brine uptake & 2 & 16 & 43 & 0.93 & Moderately sorted \\
\hline Betaine uptake & 28 & 160 & 498 & 1.75 & Poorly sorted \\
\hline Betaine flow-back & 55 & 180 & 500 & 1.92 & Poorly sorted \\
\hline ATMP uptake & 40 & 85 & 420 & 2.04 & Very poorly sorted \\
\hline ATMP flow-back & 16 & 220 & 500 & 1.73 & Poorly sorted \\
\hline Glutaraldehyde uptake & 22 & 180 & 501 & 2.10 & Very poorly sorted \\
\hline Glutaraldehyde flow-back & 22 & 220 & 502 & 2.13 & Very poorly sorted \\
\hline
\end{tabular}

and precipitation within the core is not the focus of the current study.

\section{Effect of Chemicals on Unconfined Compressive Strength (UCS) and Young's Modulus}

Figure 5 shows the pre- and post-chemical treatment uniaxial stress-strain responses for both sandstone and carbonate samples. The stress-strain curves for untreated and chemically treated sandstone (Fig. 5a) and carbonates (Fig. 5b) reveal linearly increased axial strain with increasing applied load until the sample yielded or failed. The results indicate a change in the UCS of the chemically treated sandstone and carbonate. Reduction in mean UCS of sandstone from $24 \pm 2.0$ to $21 \pm 2.0$, $14 \pm 3.4,12 \pm 0.6$ and $13 \pm 0.7 \mathrm{MPa}$, and an increase in mean strength of carbonate from $6 \pm 0.6$ to $11,13 \pm 2.8,12 \pm 2.1$ and $9 \pm 1.5 \mathrm{MPa}$ were re- 


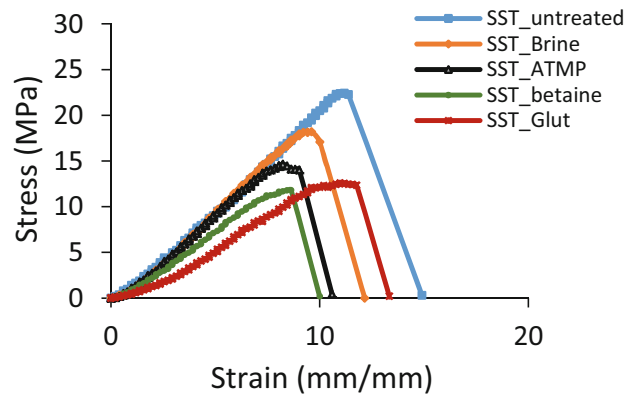

(a)

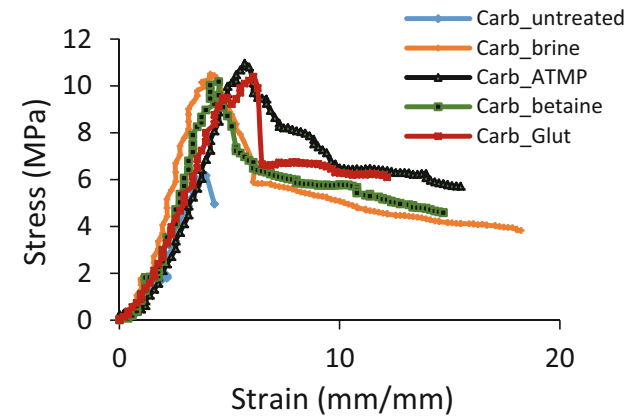

(b)

Figure 5. Stress-strain curve for untreated and chemically treated samples under dynamic condition: (a) sandstone and (b) carbonate.

Table 6. UCS and Young's modulus of treated and untreated sandstone and carbonate samples $(n=3)$ with recommended size correction factor under dynamic saturation

\begin{tabular}{|c|c|c|c|c|}
\hline & UCS (MPa) & Corrected UCS (MPa) & Length/diameter (L/D) ratio & Young's modulus (GPa) \\
\hline \multicolumn{5}{|l|}{ Sandstone } \\
\hline SST-Untreated & $24 \pm 2.0$ & $22 \pm 1.8$ & 1.3 & 19 \\
\hline SST-Brine & $21 \pm 4.0$ & $20 \pm 3.7$ & 1.3 & $13 \pm 2.8$ \\
\hline SST-ATMP & $14 \pm 3.6$ & $13 \pm 3.3$ & 1.3 & $10 \pm 3.8$ \\
\hline SST-Betaine & $12 \pm 0.6$ & $11 \pm 0.6$ & 1.3 & $10 \pm 0.7$ \\
\hline SST-Glut & $13 \pm 0.7$ & $12 \pm 0.7$ & 1.3 & $11 \pm 4.0$ \\
\hline \multicolumn{5}{|l|}{ Carbonate } \\
\hline Carb-Untreated & $6 \pm 0.6$ & $6 \pm 0.6$ & 1.3 & 6 \\
\hline Carb-Brine & $13 \pm 2.8$ & $12 \pm 2.6$ & 1.3 & $16 \pm 2.8$ \\
\hline Carb-ATMP & $11 \pm 0.1$ & $10 \pm 0.1$ & 1.3 & $10 \pm 2.8$ \\
\hline Carb-Betaine & $10 \pm 3.0$ & $9 \pm 2.8$ & 1.3 & $8 \pm 4.0$ \\
\hline Carb-Glut & $9 \pm 1.5$ & $8 \pm 1.3$ & 1.3 & $10 \pm 3.5$ \\
\hline
\end{tabular}

The correction was based on the ASTM C42-90 correction factor of 0.93

SST Sandstone, Carb Carbonate, Glut glutaraldehyde

corded owing to treatment with brine, ATMP, betaine and glutaraldehyde, respectively (Table 6). Recall that the length/diameter (L/D) ratio of the core samples is 1.3 and recognizing that rock strength is influenced by sample dimensions, ASTM standard correction factor of 0.93 (ASTM 1992) was used to correct the measured strength of core samples as presented in Table 6 .

The measured UCS of untreated and brine treated sandstone (leopard) of $24 \pm 2 \mathrm{MPa}$ is within the range of strength of 21-26 MPa declared by the supplier, Kocurek industries Ltd. On the other hand, the measured UCS of untreated carbonates (Edward brown) of $6 \pm 0.6 \mathrm{MPa}$ falls below the range 14$21 \mathrm{MPa}$ declared by Kocurek Industries Ltd. Although increase in strength was observed with the chemically treated carbonates, the observed strengths still fall below the stipulated range. The low strength of the carbonate could be attributed to its original weak nature. This could be explained by the fact that the carbonates have less favorable mechanical properties due to low degree of lithification (Durmeková et al. 2003). Wuyep et al. (2018) found an 18, 44 and $55 \%$ reduction in the UCS of sandstone samples from Niger Delta, Nigeria, exposed to ATMP, betaine and glutaraldehyde. When limestone samples from the same country were exposed to these chemicals under static condition, a 29 and $41 \%$ reduction in UCS was recorded in betaine and glutaraldehyde.

The stress-small strain response for both rocks is shown in Figure 6; the strain in this case was 


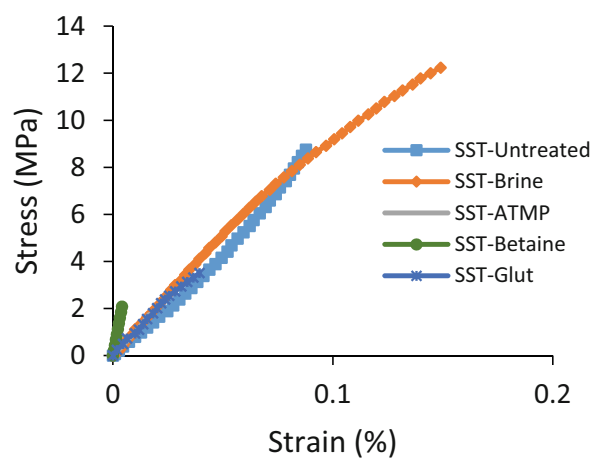

(a)

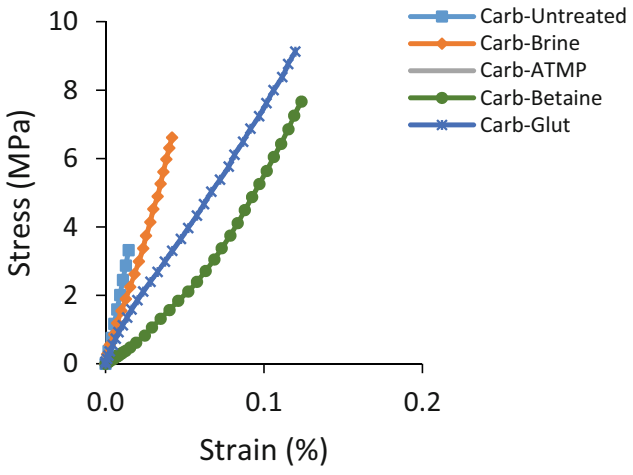

(b)

Figure 6. Stress-small strain response for untreated and chemically treated samples under dynamic condition: (a) sandstone; (b) carbonate.

measured using a strain gauge attached to the surface of the core. As expected, the stress vs. small strain relationship is linear. The Young's modulus of sandstone reduced in stiffness from 19 to $13 \pm 2.8$, $10 \pm 3.4,9.5 \pm 0.7$ and $11 \pm 4 \mathrm{GPa}$, whereas that of the carbonate increased from 6 to $16 \pm 2.8$, $10 \pm 2.8,8 \pm 4.0$ and $10 \pm 3.5 \mathrm{GPa}$ when exposed to brine, ATMP, betaine and glutaraldehyde, respectively (Table 6).

Rock strength and modulus are strongly influenced by mineral composition, grain size distribution (grain detachment) and porosity. The observed effect of the oilfield chemicals on the strength of sandstone is attributed to deterioration of the grain to grain binding. The result is consistent with previous work reported by Kahraman et al. (2008). A change in the grain to grain binding due to chemical influence leads to change in porosity and permeability leading to a reduction in the unconfined compressive strength of the cores under study.

Apart from betaine treated sandstone that fell below the range, all other determined Young's modulus values for sandstone and carbonates are within the typical range (10-20 GPa) for sandstone and (3-27 GPa) for carbonates.

Various models, for example, power law, linear, logarithmic, exponential and second-order polynomial, were used to correlate the porosity and UCS of the sandstone and carbonate to see which one fits the data best (Fig. 7). Statistically significant $(p<0.05)$ inverse relationships between uniaxial compressive strength and Young's modulus with porosity were established which can be described by any of the five laws. The sandstone and carbonate UCS-porosity data fit best into the second-order polynomial model $\left(R^{2}\right.$ of 0.9991 and 0.9892 , respectively). Similarly, relationship exists between porosity and the Young's modulus of sandstone and carbonates as presented in Table 7. Palchik (1999) has also established such relationship between porosity and UCS for sandstone in brine. These empirical relationships suggest that porosity $(\Phi)$ can be used to predict UCS and Young's modulus of sandstone and carbonate rocks within the range $20 \leq \Phi \leq 30 \%$. Despite the limited data points $(n=4)$ in this study, the UCS-porosity relationship from the current work is consistent with that for sandstone and carbonates with wide range of petrophysical properties, mineralogy and heterogeneity as shown in Fig. 8 (Palchik 1999; Palchik and Hatzor 2004; Chang et al. 2006; Sabatakakis et al. 2008; Reyer and Philipp 2014). However, a cautious approach is suggested when utilizing such empirical relationships to estimate UCS which has also been noted by Chang et al. (2006) where they indicated that porosity alone is not a good indicator of UCS in low porosity $(<5 \%)$ sandstone and carbonates. It is worth noting the wide range of data reported for both rock types which could also be linked to the measurement approach, e.g., on dry or saturated cores, static or dynamic measurements or even differences in diagenetic processes in the formations.

\section{Effect of Chemical Treatment on Mineralogy}

\section{Sandstone}

The SEM micrographs, EDX and XRPD analyses of sandstone samples post-exposure to brine, 

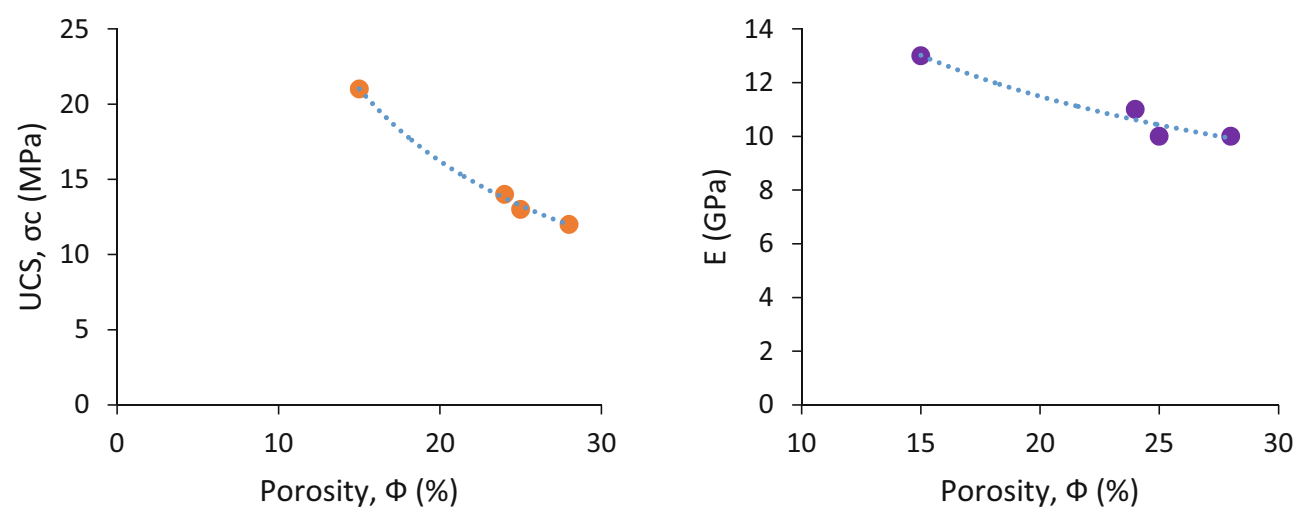

(a)
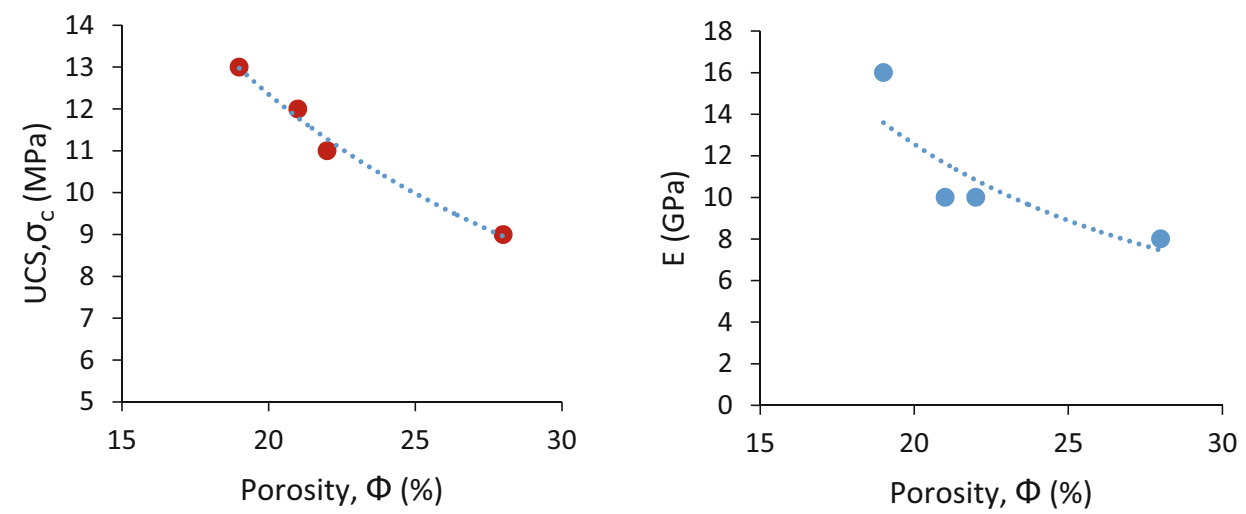

(b)

Figure 7. Relationship between porosity, UCS and Young's modulus of (a) sandstone and (b) carbonate. The dot-dot line is the second-order polynomial best fit to the experimental data.

Table 7. Summary of different models used to describe UCSporosity relationship

\begin{tabular}{llc}
\hline \multicolumn{1}{c}{ Equation } & Regression coefficient $\left(R^{2}\right)$ \\
\hline Sandstone & & \\
UCS, MPa & $\sigma=241.89 \Phi^{-0.902}$ & 0.996 \\
$E$, GPa & $E=42.169 \Phi^{-0.434}$ & 0.933 \\
Carbonates & & \\
UCS, MPa & $\sigma=215.79 \Phi^{-0.955}$ & 0.987 \\
$E$, GPa & $\sigma=1293.3 \Phi^{-1.547}$ & 0.761 \\
\hline
\end{tabular}

$\sigma$ UCS, $E$ Young's modulus and $\Phi$ porosity (\%)

betaine, ATMP and glutaraldehyde are shown in Fig. 9. SEM coupled with EDX reveals variation in morphology and silicon composition in the untreated and chemically treated samples. The significant content of silica in the samples implies that the sandstone is silica based. After chemical treatment, the SEM micrographs of the sandstone reveal pitting of the clay mineral constituents in the brine, betaine and ATMP treated sandstone without migration (circled in Fig. 9a, b and c). The pitting is believed to have resulted from dissolution/precipitation of the clay minerals during chemical-rock interaction. The presence of clay minerals in the samples increased the surface area, providing an enabling environment for ion exchange. Glutaraldehyde treated sandstone (Fig. 9d) shows spreading of altered clay and calcite grains on the surface of the larger unaltered quartz grains as indicated by the arrow in Fig. 1a in contrast to the untreated samples, which show only unaltered quartz grains.

The X-ray powder diffraction (XRPD) results of bulk mineralogical (whole rock) analysis show variations in mineralogical composition of the sam- 


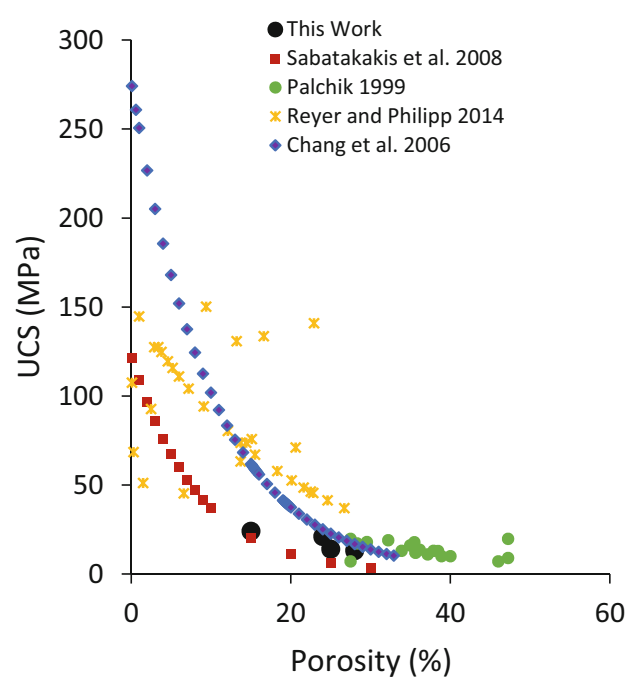

(a)

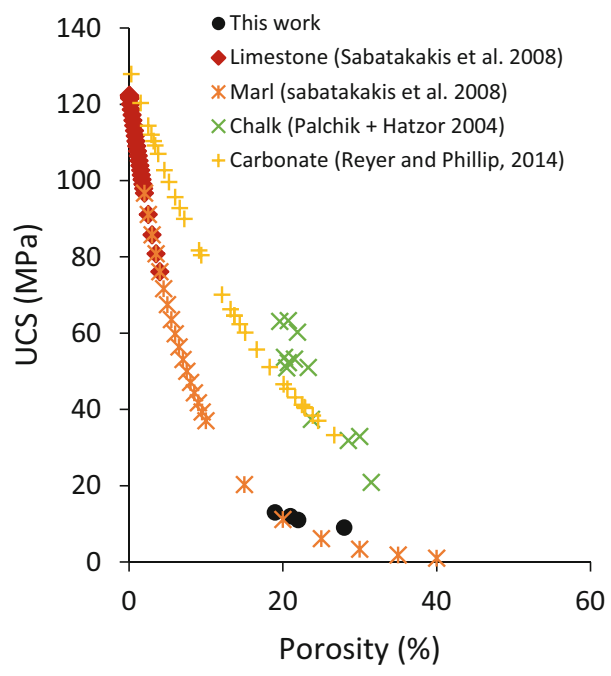

(b)

Figure 8. Comparison of the porosity-unconstrained compressive strength (UCS) relationship with existing correlations for (a) sandstone and (b) carbonates.

ples. Table 3 and Figure 10a and b reveal high content of quartz ( $\geq 98.0 \mathrm{wt} \%)$ in sandstone treated with brine, betaine, ATMP and glutaraldehyde, respectively, with little amount of plagioclase $(<0.5 \mathrm{wt} \%)$, calcite $\quad(<0.5 \mathrm{wt} \%), \quad \mathrm{I} / \mathrm{S}-\mathrm{ML}$ $(<1 \mathrm{wt} \%)$ and kaolinite $(<1 \mathrm{wt} \%)$. Quartz, which is the dominant mineral in the sandstone core sample, did not experience any observable change in the presence of the chemicals due to its non-reactive nature.

The clay minerals identified from XRPD include, kaolinite, illite and illite-smectite multi-layered (I/S-ML) (Table 4; Fig. 10c and d). Clay minerals analysis reveals a substantial increase of kaolinite from 14 to $23 \%$ with betaine and glutaraldehyde treated samples, 19 and $17 \%$ with brine and ATMP treated samples, respectively, whereas a reduction in illite from 35 to $19,12,15$ and $13 \%$ was observed, respectively, with brine, betaine, ATMP and glutaraldehyde treated samples. However, an increase in illite/smectite mixed layer (I/S-ML) from 51 to $62,65,68$ and $64 \%$ was observed with brine, betaine, ATMP and glutaraldehyde treated samples, respectively. It is noteworthy that clay minerals are very reactive in nature due to their large surface area, and, as such, they possess high adsorption capacity to chemicals (Jordan et al. 1994). Jordan et al. (1994) suggest that the interaction of the chemicals with the carbonate resulted in illite dis- solution and kaolinite precipitation. The impact of interaction is more significant with betaine and glutaraldehyde, while ATMP had more impact on I/SML.

Further analysis of the effluents using ICP-OES to determine the concentrations of $\mathrm{Na}^{+}, \mathrm{Ca}^{2+}$ and $\mathrm{Mg}^{2+}$ in treated sandstone showed insignificant difference between the uptake and flow-back elemental concentrations $(p \geq 0.05)$. However, there was a significant decrease $(47,45$ and $57 \%)$ in $\mathrm{Na}^{+}$concentration on being treated with betaine, ATMP and glutaraldehyde, respectively. Brine and ATMP effluents showed $7 \%$ increase in $\mathrm{Ca}^{2+}$ concentration, whereas a 16 and $25 \%$ decrease in $\mathrm{Ca}^{2+}$ was observed with betaine and glutaraldehyde effluents, respectively $(p \geq 0.05) . \mathrm{Mg}^{2+}$ concentration increased by 21,2 and $8 \%$ in brine, betaine and ATMP effluents, respectively, but decreased by $10 \%$ in glutaraldehyde effluent. The changes in the elemental $\left(\mathrm{Na}^{+}, \mathrm{Ca}^{2+}\right.$ and $\mathrm{Mg}^{2+}$ concentrations observed could be attributed to the possible adsorption of the species (reduced effluent concentration) and dissolution from the cores (increased specie concentrations). This result is consistent with the description of adsorption by Bolt et al. (1976).

It has been observed from the results that the strength (UCS) of sandstone decreased with increase in porosity, $\mathrm{D}_{50}$ with poor sorting, concentration of kaolinite, I/S-ML and a decrease in illite 


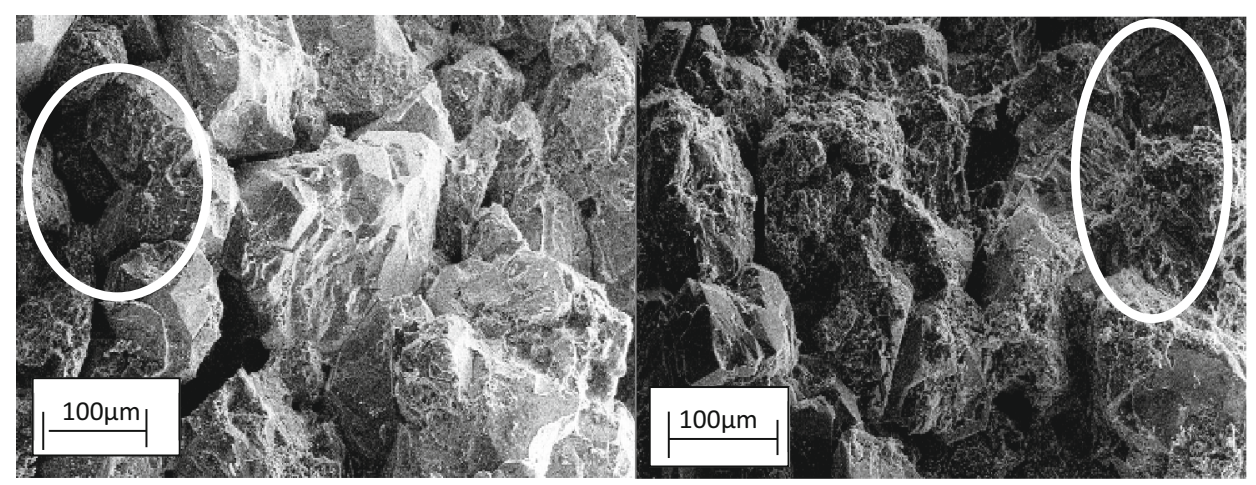

(a)

(b)

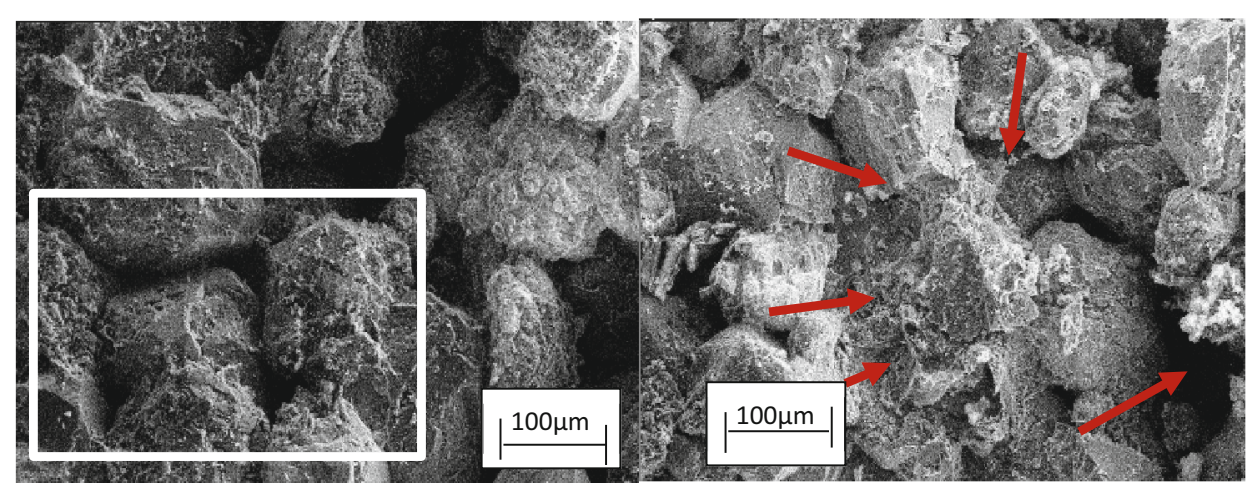

(c)

(d)

Figure 9. SEM micrographs of the sandstone after exposure to (a) brine showing pitting within the white ellipse; (b) betaine showing pitting within the white ellipse; (c) ATMP showing pitting within the white square; and (d) glutaraldehyde showing spreading of altered clay and calcite grains on the surface of the larger unaltered quartz grains locations identified by the arrows.

following exposure to the chemicals used in the study (Table 8). XRPD results clearly show that clay minerals form the major cementing materials of the sandstone. The decrease (illite)/increase (kaolinite and $\mathrm{I} / \mathrm{S}-\mathrm{ML}$ ) of the clay content following chemical treatment suggests dissolution/precipitation reaction within the sandstone. It is known that porosity is one of the bridges that link both particle size distribution and other properties of the materials (Wang et al. 1999). Therefore, the relationship between other parameters (particle size distribution, sorting and mineralogy) and UCS has been revealed through the inverse relationship between the porosity and the UCS (Fig. 7a). The changes in the cementing materials due to chemical treatment caused a release of disintegrated grains into the fluid streams, creating voids in the sandstone samples that led to porosity increase, hence decrease in UCS as a result of weakened grain fabrics, with a consequence of sand failure.

\section{Carbonate}

The SEM micrograph shows some altered, pitted, disengaged grains and spreading of altered grains over unaltered grains in brine, betaine, ATMP and glutaraldehyde treated carbonate, respectively (Fig. 11). EDX result shows abundance of calcium, magnesium, carbon and oxygen elements typical of dolomite (Table 2). The X-ray powder diffraction (XRPD) of whole rock analysis reveals that the carbonate contains majorly dolomite with an increase in weight percent (wt \%) from 73.8 to 92.6, 93.0, 93.6 and 95.1 after treatment with brine, betaine, ATMP and glutaraldehyde, respectively (Fig. 12a and b; Table 3). The concentration of calcite reduced in weight percent (wt\%) from 21.2 to 2.3, 2.2 and 1.6 in the presence of brine, betaine, ATMP and glutaraldehyde, respectively. A slight increase in the concentration of quartz from 3.7 to 4.0 and $4.2 \mathrm{wt} \%$ is observed in brine and betaine 


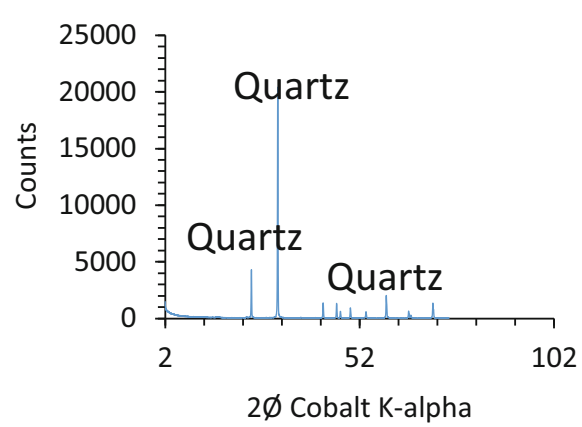

(a)

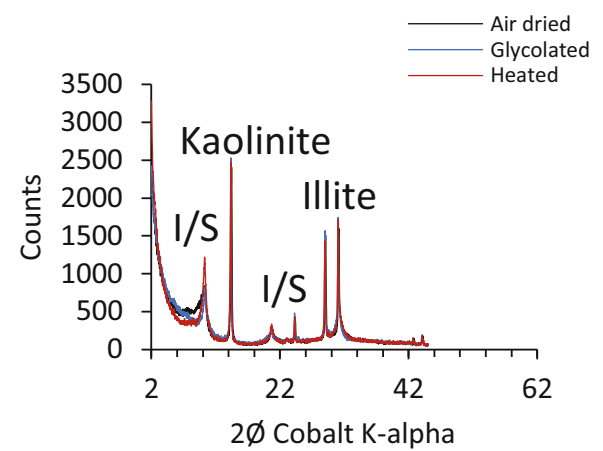

(c)

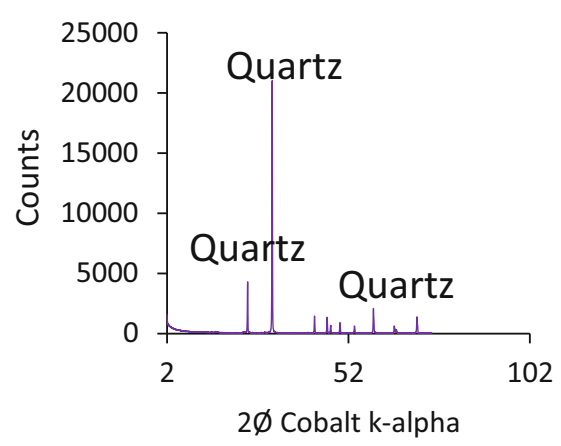

(b)

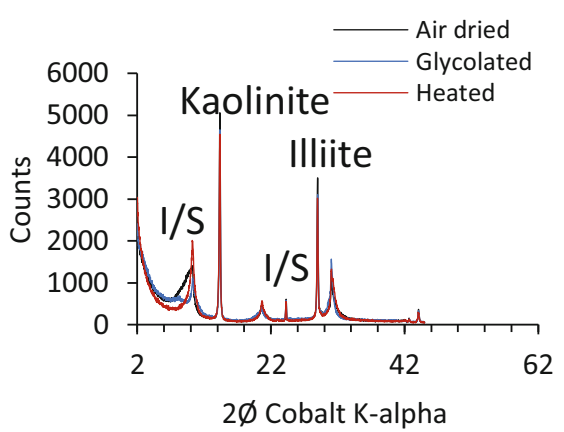

(d)

Figure 10. Bulk mineralogy and clay fraction characterization of treated sandstone with: (a) brine, XRPD; (b) betaine, XRPD; (c) brine, clay fraction; and (d) betaine, clay fraction.

Table 8. Summary of the effects of chemicals on particle size distribution, porosity, mineralogy and UCS of sandstone and carbonates

\begin{tabular}{|c|c|c|c|c|c|c|c|c|c|}
\hline \multirow[t]{2}{*}{ Sample ID } & \multirow{2}{*}{$\begin{array}{l}\text { Mean } D_{50} \\
\qquad(\mu \mathrm{m})\end{array}$} & \multirow{2}{*}{$\begin{array}{l}\text { Porosity } \\
\qquad(\%)\end{array}$} & \multicolumn{6}{|c|}{ Mineralogy } & \multirow{2}{*}{$\begin{array}{l}\text { ASTM corrected } \\
\text { UCS } \\
(\mathrm{MPa})\end{array}$} \\
\hline & & & $\begin{array}{l}\text { Quartz } \\
\text { (wt } \%)\end{array}$ & $\begin{array}{l}\text { Dolomite } \\
(\mathrm{wt} \%)\end{array}$ & $\begin{array}{l}\text { Calcite } \\
(\text { wt } \%)\end{array}$ & $\begin{array}{c}\text { Kaolinite } \\
(\%)\end{array}$ & $\begin{array}{l}\text { Illite } \\
(\%)\end{array}$ & $\begin{array}{c}\text { I/S-ML } \\
(\%)\end{array}$ & \\
\hline \multicolumn{10}{|l|}{ Sandstone } \\
\hline SST-Untreated & N/A & N/A & 98.4 & N/A & 0.4 & 14 & 35 & 51 & 22 \\
\hline SST-Brine & 20 & 21 & 98.5 & N/A & 0.1 & 19 & 19 & 62 & 20 \\
\hline SST-Betaine & 165 & 28 & 98.0 & N/A & 0.1 & 23 & 12 & 68 & 11 \\
\hline SST-ATMP & 117 & 25 & 98.4 & N/A & 0.2 & 17 & 15 & 65 & 13 \\
\hline SST-Glut & 100 & 24 & 98.0 & N/A & 0.4 & 23 & 13 & 64 & 12 \\
\hline \multicolumn{10}{|l|}{ Carbonate } \\
\hline Carb-Untreated & N/A & N/A & 3.7 & 73.8 & 21.2 & 7 & 7 & 86 & 6 \\
\hline Carb-Brine & 16 & 28 & 4.0 & 92.6 & 2.3 & 10 & 6 & 84 & 12 \\
\hline Carb-Betaine & 170 & 22 & 4.2 & 93.0 & 2.2 & 10 & 4 & 84 & 9 \\
\hline Carb-ATMP & 153 & 21 & 3.8 & 93.6 & 1.6 & 9 & 5 & 86 & 10 \\
\hline Carb-Glut & 200 & 19 & 2.8 & 95.1 & 1.6 & 8 & 6 & 86 & 8 \\
\hline
\end{tabular}

treated carbonate, respectively, while there is little or no change in ATMP treated carbonate (3.8 wt \%) and a decrease to $2.8 \mathrm{wt} \%$ is observed in glu- taraldehyde treated carbonate. The reduction and increment in the concentration of calcite and dolomite, respectively, supports the view of dissolu- 


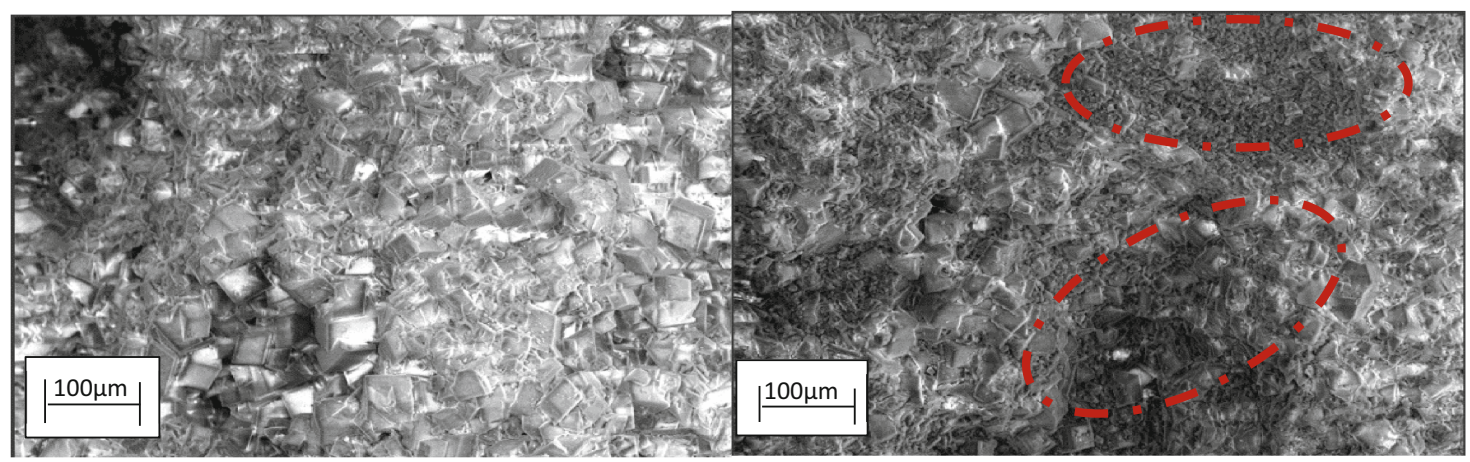

(a)

(b)

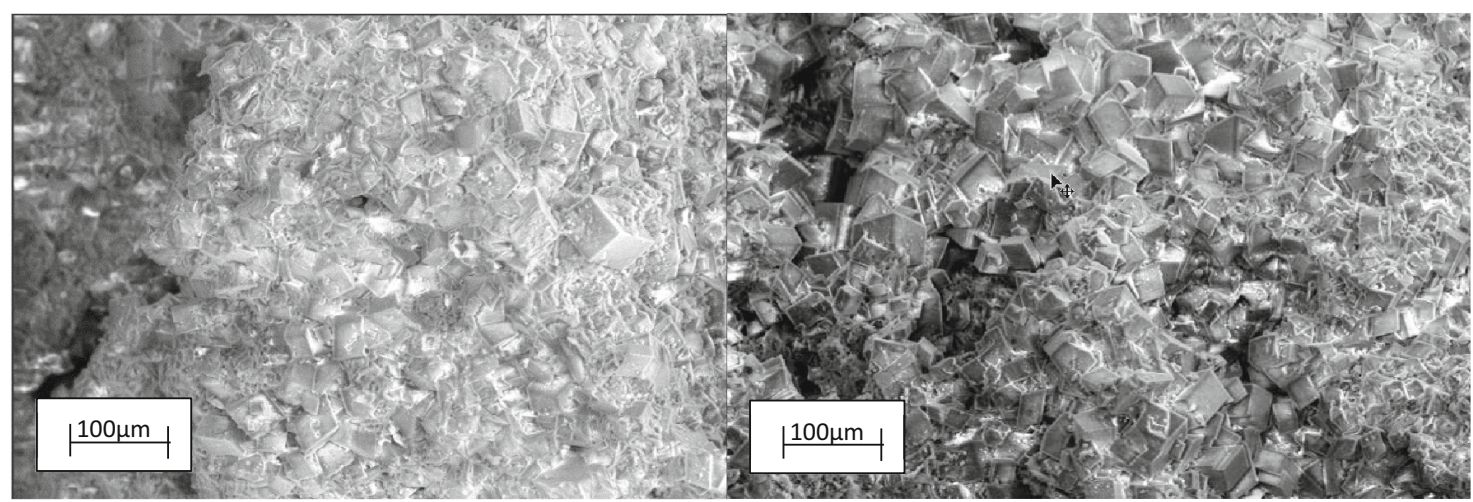

(c)

(d)

Figure 11. Carbonate post-chemical treatment SEM micrograph showing filled pore spaces with: (a) brine treated; (b) betaine treated with pitting within the dotted ellipse; (c) ATMP treated; and (d) glutaraldehyde treated.

tion/precipitation reaction as discussed earlier. Oluyemi (2014) had suggested that ionic substitution reaction between the chemical species and the brine could lead to the formation and deposition of new materials in the pores. However, precipitation reaction dominates in the interaction between carbonate rocks and the chemicals. Consumption of calcite leads to production of dolomitic minerals at a flow rate of $0.25 \mathrm{~mL} / \mathrm{min}$. ATMP-carbonate interaction influenced a change in $\mathrm{pH}$ from 1 to 5 which changed the $\mathrm{Ca}^{2+}$ release into the effluent from $270 \mathrm{mg} / \mathrm{L}$ at $\mathrm{pH} 1$ to $347 \mathrm{mg} / \mathrm{L}$ (uptake) and $319 \mathrm{mg} /$ L (flow-back) at pH 5.

Again, changes in concentrations of $\mathrm{Na}^{+}, \mathrm{Ca}^{2+}$ and $\mathrm{Mg}^{2+}$ were also observed in chemically treated carbonate. Brine effluent showed $72 \%$ increase in $\mathrm{Na}^{+}$concentration, while betaine, ATMP and glutaraldehyde effluents showed 40,61 and $65 \%$ decrease in $\mathrm{Na}^{+}$concentration, respectively. Similarly, betaine and glutaraldehyde effluents indicated 24 and $35 \%$ decrease in $\mathrm{Ca}^{2+}$ concentration, while brine and ATMP showed 6 and 23\% increase, respectively. No change was observed with $\mathrm{Mg}^{2+}$ concentration in betaine effluent. However, 25, 24 and 19\% increase of $\mathrm{Mg}^{2+}$ concentration was observed in the brine, ATMP and glutaraldehyde effluents, respectively. The result suggests that while $\mathrm{Na}^{+}$and $\mathrm{Ca}^{2+}$ were being adsorbed by the rock, $\mathrm{Mg}^{2+}$ was released into the effluent.

Three simultaneous reaction mechanisms are possible with calcite dissolution process (Plummer et al. 1978). In the current study, the likely reaction involving the ionic exchange during calcite dissolution and dolomite precipitation when the carbonate rock was exposed to the chemicals are presented below in Eqs. (1)-(4):

$$
\begin{gathered}
\mathrm{CaCO}_{3} \stackrel{\mathrm{H}^{+}}{\leftrightarrow} \mathrm{Ca}^{2+}+\mathrm{HCO}_{3}^{-} \\
\mathrm{CaCO}_{3}+\mathrm{H}_{2} \mathrm{CO}_{3}^{0} \leftrightarrow 2 \mathrm{HCO}_{3}^{-} \\
\mathrm{CaCO}_{3}+\mathrm{H}_{2} \mathrm{O} \leftrightarrow \mathrm{Ca}^{2+}+\mathrm{HCO}_{3}^{-}+\mathrm{OH}^{-}
\end{gathered}
$$




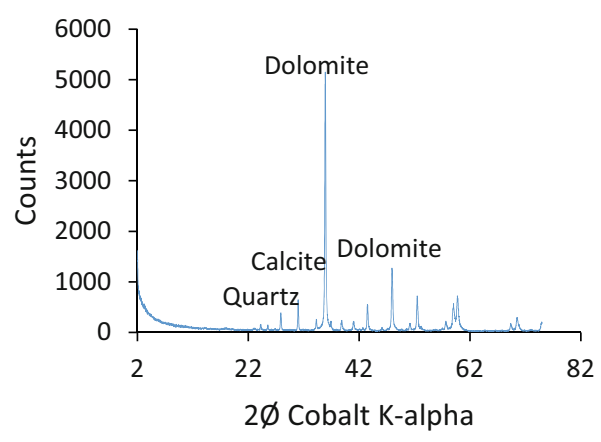

(a)

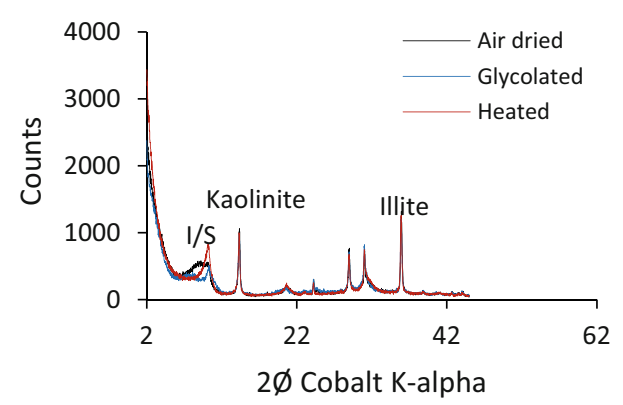

(c)

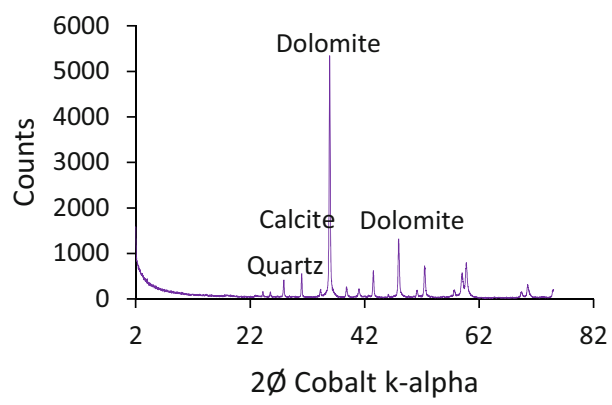

(b)

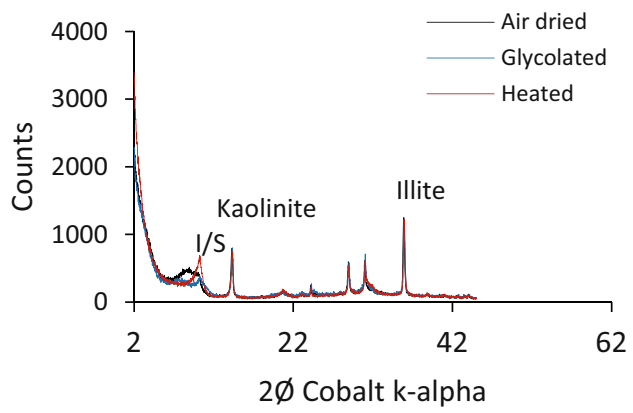

(d)

Figure 12. Bulk mineralogy (wt \%) and clay fraction characterization of treated carbonate: (a) brine, XRPD; (b) betaine, XRPD; (c) brine, clay fraction; and (d) betaine, clay fraction.

$$
\mathrm{Ca}^{2+}+\mathrm{Mg}^{2+}+2 \mathrm{C}^{+}+7 \mathrm{O}^{-} \stackrel{2 \mathrm{H}^{+}}{\leftrightarrow} \mathrm{CaMg}\left(\mathrm{CO}_{3}\right)_{2}+\mathrm{H}_{2} \mathrm{O}
$$

The XRPD analysis of clay minerals shows an increase in kaolinite composition from 7 to $10 \%$ owing to brine and betaine treatment; $9 \%$ due to ATMP treatment with marginal change $(8 \%)$ in glutaraldehyde treated limestone (Fig. 12c and d; Table 4). Illite reduced from 7 to 4 and $5 \%$ in the presence of betaine and ATMP with little reduction $(6 \%)$ in the presence of brine and glutaraldehyde. Again, illite dissolved to precipitate kaolinite as evidenced by the reduction in the relative contents of illite in the presence of the chemicals. High content $(86 \%)$ of illite/smectite mixed layer (I/S-ML) was obtained which remain constant in the presence of the chemicals. Some clay minerals such as smectite, illite, I/S-ML are well known for expandability, which causes constriction of pore throat. This accounts for reduced pore volume, porosity and permeability discussed in "Effect of Chemicals on Porosity and Permeability of Sandstone and Carbonate" section. This research has indicated the possibility of the inhibitors, especially ATMP and betaine forming complexes with the divalent cations $\left(\mathrm{Ca}^{2+}, \mathrm{Mg}^{2+}\right)$ that eventually precipitate. This has been previously reported by (Tantayakom et al. 2004). The current work has indicated that pore constriction can still take place irrespective of the initial $\mathrm{pH}$ of the injected chemicals; this agrees with Singurindy and Berkowitz (2003) findings.

Overall, the results of the effect of chemicals on carbonates revealed an increase in UCS with a decrease in porosity, increase in $\mathrm{D}_{50}$ with very poorly sorting, dolomite content and a decrease in calcite and kaolinite content following chemicals treatment (Table 8 ). The change might have been caused by dissolution/precipitation reaction following treatment with betaine, ATMP and glutaraldehyde. Calcite and dolomite were revealed by XRPD to be the cementing materials. The filling of the pore space by these precipitates led to a decrease in porosity and an increase in the UCS of the carbonates. The carbonates being heterogeneous are expected to have lost their permeability to the interaction (Mohamed and Nasr-El-Din 2013); however, the opposite was observed in this study. It 
is noteworthy that the precipitates that filled the pore space providing a false strength increase may not be as strong as the disintegrated original materials as such there is a possibility that sand can fail leading to sand production.

\section{CONCLUSIONS}

The interaction between reservoir formation rocks and three commonly used oilfield chemicals (biocide, corrosion inhibitor and scale inhibitor) has been evaluated under dynamic condition. Clastic and carbonate cores obtained from Texas, USA, through Kocurek industries were used in the study. Both mechanical and analytical tests were deployed to characterize the cores pre- and post-chemical treatments and analyses the interaction between the chemicals and the rocks. The results suggest that chemical interactions in the form of adsorption, dissolution/precipitation and ionic substitution took place between the oilfield chemicals and the rocks. The dissolution reaction caused deterioration of the rocks grain to grain binding, leading to release of disintegrated grains into the fluid streams. The release of the grains caused porosity increase and reduction in unconfined compressive strength of sandstone, a phenomenon that can lead to sand failure and production in reservoir rocks. On the other hand, the precipitated particles may fill the pore space leading to porosity and permeability reduction. Such pore constriction potentially leads to formation damage, the consequence of which is formation damage, sand production and productivity/injectivity impairment.

These same chemicals used in the current study were used to saturate real reservoir sandstone and limestone under static condition as reported by Wuyep et al. (2018) and were found to cause strength reduction in both rock types, which is contrary to the strength increase observed with carbonate in the current work. The difference in the effect on the strength of limestone and carbonate could be attributed to the homogeneous and heterogeneous nature of the limestone and carbonate, respectively. Further comparison of post-treatment particle size distribution shows a 79 and $77 \%$ increase in $\mathrm{D}_{50}$ of sandstone and limestone, respectively, under static condition relative to 84 and $91 \%$ increase in $\mathrm{D}_{50}$ of sandstone and carbonate, respectively, under dynamic condition.
It is important that field operators take note of the undesirable geomechanical effects of these oilfield chemicals on the reservoir and factor them into the evaluation of failure and sand production potential of the reservoir rocks.

\section{ACKNOWLEDGMENTS}

The authors gratefully acknowledge Petroleum Technology Development Fund (PTDF), Nigeria, for funding the $\mathrm{PhD}$ work from which the materials and results presented in this paper originated. The authors are also grateful to the Laboratory technicians in the School of Pharmacy and Life science and Gray School of arts, Robert Gordon University; and School of Engineering, University of Aberdeen for their technical support.

\section{OPEN ACCESS}

This article is distributed under the terms of the Creative Commons Attribution 4.0 International License (http://creativecommons.org/licenses/by/4.0/ ), which permits unrestricted use, distribution, and reproduction in any medium, provided you give appropriate credit to the original author(s) and the source, provide a link to the Creative Commons license, and indicate if changes were made.

\section{REFERENCES}

ASTM. (1992). Standard test method for obtaining and testing method for obtaining and testing drilled cores and sawed beams of concrete (Vol. 4, pp. C42-C90)., 1991 annual book of ASTM standards, concrete and aggregates West Conshohocken: ASTM.

Baraka-Lokmane, S., \& Sorbie, K. S. (2010). Effect of pH and scale inhibitor concentration on phosphonate-carbonate interaction. Journal of Petroleum Science and Engineering, 70, 10-27.

Benavente, D., del Cura, Mag, Fort, R., \& Ordonez, S. (2004). Durability estimation of porous building stones from pore structure and strength. Engineering Geology, 74(1), 113-127.

Bernabé, Y., Mok, U., \& Evans, B. (2003). Permeability-porosity relationships in rocks subjected to various evolution processes. Pure and Applied Geophysics, 160(5), 937-960.

Bieniawski, Z., \& Bernede, M. (1979). Suggested methods for determining the uniaxial compressive strength and deformability of rock materials: Part 1 . Suggested method for determining deformability of rock materials in uniaxial compression. International Journal of Rock Mechanics and 
Mining Sciences \& Geomechanics Abstracts. Elsevier, 16(02), 138-140.

Bolt, G. H., Bruggenwert, M. G. M., \& Kamphorst, A. (1976). Adsorption of cations by soils. In G. H. Bolt \& M. G. M. Bruggenwert (Eds.), Soil chemistry. A. Basic elements. Amsterdam: Elsevier.

Bunny, J., Jordan, M., \& Sorbie, K. (1997). The prediction and avoidance of formation damage induced by scale inhibitor squeeze treatments. In SPE European formation damage conference, The Hague, 2-3 June.

Chang, C., Zoback, M. D., \& Khaksar, A. (2006). Empirical relations between rock strength and physical properties in sedimentary rocks. Journal of Petroleum Technology, 51, 223-237.

Durmeková, T., Holzer, R., \& Wagner, P. (2003). Weak rocks in engineering practice. In Natsu, Fecker \& Pimentel (Eds.), Conference proceedings, geotechnical measurements and modelling (pp. 185-191). Lisse: Swets \& Zeitlinger.

Edupack, C. E. S. (2018). Cambridge engineering selector. Cambridge: Granta Designs Limited.

Egermann, P., Bekri, S., \& Vizika, O. (2010). An integrated approach to assess the petrophysical properties of rocks altered by rock-fluid interactions $\left(\mathrm{CO}_{2}\right.$ injection). Petrophysics, $51(01), 32-40$

Folk, R. L. (1966). A review of grain-size parameters. Sedimentology, 6(2), 73-93.

Jordan, M. M., \& Sjursaether, K. (2005). Scale control within sea chalk/limestone reservoirs. The challenge of understanding and optimizing chemical placement methods and retention mechanism: Laboratory to field. SPE 86476. Paper presented at the SPE international symposium and exhibition on formation damage control. Lafayette, Louisiana, USA, 18-20 February.

Jordan, M., Sorbie, K., Ping, J., Yuan, M. D., Todd, A., \& Hourston, K. (1994). Phosphonate scale inhibitor adsorption/ desorption and the potential for formation damage in reconditioned field core. In SPE formation damage control symposium. Society of Petroleum Engineers.

Kahraman, S., Gunaydin, O., \& Fener, M. (2008). The effect of water saturation on the strength of marbles. In ISRM international symposium-5th Asian rock mechanics symposium. International Society for Rock Mechanics.

Kan, A. T., Fu, G., Tomson, M. B., Al-Thubaiti, M., \& Xiao, A. J. (2004). Factors affecting scale inhibitor retention in carbonate-rich formation during squeeze treatment. SPE Journal, 9(3), 280-289. SPE80230-PA.

Kan, A. T., Fu, G. M., \& Tomson, M. B. (2005). Adsorption and precipitation of an aminoalkylphosphonate onto calcite. Journal of Colloid and Interface Science, 281(2), 275-284.

Lamy-Chappuis, B., Angus, D., Fisher, Q., Grattoni, C., \& Yardley, B. (2014). Rapid porosity and permeability changes of calcareous sandstone due to $\mathrm{CO}_{2}$-enriched brine injection. Geophysical Research Letters, 41(2), 399-406.

Li, L., \& Aubertin, M. (2003). A general relationship between porosity and uniaxial strength of engineering materials. Canadian Journal of Civil Engineering, 30(4), 644-658.

Mohamed, I., \& Nasr-El-Din, H. A. (2013). Fluid/rock interactions during $\mathrm{CO}_{2}$ sequestration in deep saline carbonate aquifers: Laboratory and modelling studies. SPE Journal, 18(03), 468-485.

Nelson, P. H. (1994). Permeability-porosity relationships in sedimentary rocks. The Log Analyst, 35, 38-62.

Nimmo, J. (2004). Porosity and pore size distribution. Encyclopedia of Soils in the Environment, 3, 295-303.

Oluyemi, G. (2014). Conceptual physicochemical models for scale inhibitor-formation rock interaction. Petroleum Science and Technology, 32(3), 253-260.

Oluyemi, G. F., Oyeneyin, B. M., \& Macleod, C. (2010). UCS neural network model for real time sand prediction. International Journal of Engineering Research in Africa, 2, 1-13.
Palchik, V. (1999). Technical note: Influence of porosity and elastic modulus on uni-axial compressive strength in soft brittle porous sandstones. Rock Mechanics and Rock Engineering, 32(4), 303-309.

Palchik, V., \& Hatzor, Y. (2004). The influence of porosity on tensile and compressive strength of porous chalks. Rock Mechanics and Rock Engineering, 37(4), 331-341.

Plummer, L. N., Wigley, T. M. L. \& Parkhurst, D. L. (1978). The kinetics of calcite dissolution in $\mathrm{CO}_{2}$-water systems at 5 degrees to 60 degrees $\mathrm{C}$ and 0.0 to $1.0 \mathrm{~atm} \mathrm{CO}_{2}$. American Journal of Science, 278(2), 179-216.

Prrikryl, R. (2001). Some microstructural aspects of strength variation in rocks. International Journal of Rock Mechanics and Mining Sciences, 38(5), 671-682.

Ramachandran, S., Jovancicevic, V., \& Ward, M. B. (1999). Understanding interactions between corrosion inhibitors \& iron carbonate films using molecular modelling (paper no. 7). Houston: NACE International.

Reyer, D., \& Philipp, S. (2014). Empirical relations of rock properties of outcrop and core samples from the Northwest German Basin for geothermal drilling. Geothermal Energy Science, 2, 21-37.

Sabatakakis, N., Koukis, G., Tsiambaos, G., \& Papanakli, S. (2008). Index properties and strength variation controlled by microstructure for sedimentary rocks. Engineering Geology, 97(1), 80-90.

Singurindy, O., \& Berkowitz, B. (2003). Flow, dissolution, and precipitation in dolomite. Water Resources Research, 39(6), 1143. https://doi.org/10.1029/2002WR001624.

Tantayakom, V., Fogler, H., de Moraes, F., Bualuang, M., Chavadej, S., \& Malakul, P. (2004). Study of Ca-ATMP precipitation in the presence of magnesium ion. Langmuir, 20(6), 2220-2226.

Tomson, M., Kan, A., Fu, G., Shen, D., Nasr-El-Din, H., Saiari, H., et al. (2008). Mechanistic understanding of rock/phosphonate interactions and effect of metal ions on inhibitor retention. SPE Journal, 13(03), 325-336.

Török, Á., \& Vásárhelyi, B. (2010). The influence of fabric and water content on selected rock mechanical parameters of travertine, examples from Hungary. Engineering Geology, 115(3), 237-245.

Vazquez, O., Herrero, P., Mackay, E. J., \& Jordan, M. (2016). Non-aqueous overflush scale inhibitor squeeze treatment in an oilfield offshore Norway. Journal of Petroleum Science and Engineering, 138, 1-10.

Verwall, W., \& Mulder, A. (2000). Rock and aggregate test procedures. Rock and aggregate laboratory manual (pp. 13, 14).

Wang, A., Zhang, C., \& Zhang, N. (1999). The theoretic analysis of the influence of the particle size distribution of cement system on the property of cement. Cement and Concrete Research, 29, 1721-1726.

Wilson, A. (2016). Chemical analysis of flowback water and downhole gas-shale samples. Journal of Petroleum Technology, 68(09), 114-115.

Wuyep, E., Oluyemi, G., Yates, K., \& Akisanya, A. (2018). Geomechanical effects of oilfield chemicals on sand failure in reservoir rocks. Journal of Petroleum Science and Engineering, 165, 347-357.

Xue, T., Xiang, Y., \& Guo, F. (2004). Numerical method to determine mechanical parameters of engineering design in rock masses. Journal of Zhejiang University-SCIENCE, 5(7), 884-889.

Yang, L., Xu, T., Liu, K., Peng, B., Yu, Z., \& Xu, X. (2017). Fluidrock interactions during continuous diagenesis of sandstone reservoirs and their effects on reservoir porosity. Sedimentology. The Journal of the International Association of Sedimentologists, 64(5), 1303-1321. 